\title{
Emerging Therapies in Traumatic Brain Injury
}

\author{
Patrick M. Kochanek, MD, MCCM ${ }^{1,2,6}$ Travis C. Jackson, PhD ${ }^{1,2}$ Nikki Miller Ferguson, MD ${ }^{1,2,6}$ \\ Shaun W. Carlson, PhD ${ }^{1,3}$ Dennis W. Simon, MD ${ }^{1,2,6}$ Erik C. Brockman, MD ${ }^{1,2,6}$ jing Ji, MD, PhD ${ }^{1,2}$ \\ Hülya Bayır, MD ${ }^{1,2,6,7}$ Samuel M. Poloyac, PharmD, PhD ${ }^{1,8}$ Amy K. Wagner, MD ${ }^{1,4}$ \\ Anthony E. Kline, PhD ${ }^{1,4}$ Philip E. Empey, PharmD, PhD, BCPS ${ }^{1,8}$ Robert S.B. Clark, MD $1,2,6$ \\ Edwin K. Jackson, $\mathrm{PhD}^{1,5}$ C. Edward Dixon, $\mathrm{PhD}^{1,3}$
}

${ }^{1}$ Safar Center for Resuscitation Research, University of Pittsburgh
School of Medicine, Pittsburgh, Pennsylvania
${ }^{2}$ Departments of Critical Care Medicine, University of Pittsburgh
School of Medicine, Pittsburgh, Pennsylvania
${ }^{3}$ Department of Neurological Surgery, University of Pittsburgh School
of Medicine, Pittsburgh, Pennsylvania
${ }^{4}$ Department of Physical Medicine and Rehabilitation, University of
Pittsburgh School of Medicine, Pittsburgh, Pennsylvania
${ }^{5}$ Department of Pharmacology and Chemical Biology, University of
Pittsburgh School of Medicine, Pittsburgh, Pennsylvania
${ }^{6}$ Department of Pediatrics, University of Pittsburgh School of
Medicine, Pittsburgh, Pennsylvania
${ }^{7}$ Department of Environmental and Occupational Health, University of
Pittsburgh School of Public Health, Pittsburgh, Pennsylvania
${ }^{8}$ University of Pittsburgh School of Pharmacy, Pittsburgh, Pennsylvania

Address for correspondence Patrick M. Kochanek, MD, MCCM, Safar Center for Resuscitation Research, 3434 Fifth Avenue, University of Pittsburgh School of Medicine, Pittsburgh, PA 15260

(e-mail: kochanekpm@ccm.upmc.edu).

Semin Neurol 2015;35:83-100.

\begin{abstract}
Keywords

- head injury

- concussion

- neurocritical care

- treatment

- drugs

- excitotoxicity

- inflammation

- oxidative stress

- regeneration

- rehabilitation

- secondary injury

Despite decades of basic and clinical research, treatments to improve outcomes after traumatic brain injury (TBI) are limited. However, based on the recent recognition of the prevalence of mild TBI, and its potential link to neurodegenerative disease, many new and exciting secondary injury mechanisms have been identified and several new therapies are being evaluated targeting both classic and novel paradigms. This includes a robust increase in both preclinical and clinical investigations. Using a mechanismbased approach the authors define the targets and emerging therapies for TBI. They address putative new therapies for TBI across both the spectrum of injury severity and the continuum of care, from the field to rehabilitation. They discussTBI therapy using 11 categories, namely, (1) excitotoxicity and neuronal death, (2) brain edema, (3) mitochondria and oxidative stress, (4) axonal injury, (5) inflammation, (6) ischemia and cerebral blood flow dysregulation, (7) cognitive enhancement, (8) augmentation of endogenous neuroprotection, (9) cellular therapies, (10) combination therapy, and (11) TBI resuscitation. The current golden age of TBI research represents a special opportunity for the development of breakthroughs in the field.
\end{abstract}

Despite decades of basic and clinical research, treatments to improve outcomes after traumatic brain injury (TBI) are limited. In severe TBI, with few exceptions, supportive measures such as controlling brain swelling using osmolar therapy or barbiturates, and/or surgical interventions remain the standard of care. In severe TBI, development of novel therapies targeting secondary injury has been the topic of consid- erable research, but failures in translation continue to mount with the recently published clinical trial on erythropoietin ${ }^{1}$ and recent halting of the PROTECT trial of progesterone therapy (personal communication, David Wright, MD). Only treatment with amantadine in the subacute phase has translated-from the controlled cortical impact (CCI) model of TBI in rats to moderate-severe TBI in humans. ${ }^{2}$ In mild TBI
Issue Theme Traumatic Brain Injury; Guest Editor, Geoffrey Ling, MD, PhD, FAAN, FANA
Copyright (C) 2015 by Thieme Medical Publishers, Inc., 333 Seventh Avenue, New York, NY 10001, USA.

Tel: +1(212) 584-4662.
DOI http://dx.doi.org/ $10.1055 / \mathrm{s}-0035-1544237$. ISSN 0271-8235. 
(mTBI), empiric therapies targeting sequelae such as cognitive impairment and posttraumatic stress disorder are often used. However, there has been little research on therapies in mTBI, secondary injury pathways, or the link between mTBI and neurodegenerative disease. Given the increased recognition of the scope of the problem, the growth in funding for TBI research, and the expanding discussion of therapies, ${ }^{3}$ an acceleration of research into the treatment of TBI across the injury spectrum is emerging and there is cause for optimism. Using a mechanism-based approach we will define the targets and emerging therapies for TBI. We will address emerging therapies for TBI across the spectrum of severity and the continuum of care, from the field to rehabilitation. We will discuss TBI therapy using 11 categories, namely, (1) excitotoxicity and neuronal death, (2) brain edema, (3) mitochondria and oxidative stress, (4) axonal injury, (5) inflammation, (6) ischemia and cerebral blood flow (CBF) dysregulation, (7) cognitive enhancement, (8) augmentation of endogenous neuroprotection, (9) cellular therapies, (10) combination therapy, and (11) TBI resuscitation.

\section{Therapies Targeting Excitotoxicity and Neuronal Death}

Excitotoxicity and its link to neuronal death pathways in TBI has been richly explored, and yet after 45 years of research most antiexcitotoxic therapies have failed to translate. ${ }^{4,5} \mathrm{New}$ understanding of glutamatergic neurotransmission inspires optimism that future drugs will be more effective.

\section{Excitotoxicity after Traumatic Brain Injury}

Presynaptic glutamate release depolarizes post-synaptic neurons by opening ion channels such as $\mathrm{N}$-methyl-D-aspartate receptors (NMDARs) that permit $\mathrm{Na}^{+}$and $\mathrm{Ca}^{2+}$ to surge into cells. Excitotoxic events occur early after TBI and trigger apoptosis, necrosis, necroptosis, autophagy, or pyroptosis (none of which are mutually exclusive). $\mathrm{Ca}^{2+}$ overload is a key feature that is upstream to cell-death signaling. ${ }^{6} \mathrm{Na}^{+}$ overload is less significant, but may contribute to neuronal swelling. ${ }^{7}$ After TBI, there is a surge in extracellular glutamate followed by persistent elevations. ${ }^{8}$ Extracellular glutamate increases intracellular $\mathrm{Ca}^{2+}\left(\mathrm{iCA}^{2+}\right)$ by activating neuronal glutamate receptors (GluRs) like NMDARs and $\alpha$-amino3-hydroxy-5-methyl-4-isoxazolepropionic acid receptors (AMPARs). Release of $\mathrm{Ca}^{2+}$ from intracellular stores in organelles also contributes to excitotoxicity. ${ }^{9}$

\section{Necrosis and Apoptosis}

Nuclear $\mathrm{Ca}^{2+}$ promotes neuronal survival by inducing protective genes like brain-derived neurotrophic factor (BDNF). In contrast, cytoplasmic $\mathrm{Ca}^{2+}$ is toxic. Necrotic death is triggered in part by calpains- $\mathrm{Ca}^{2+}$ activated cysteine proteases that destroy survival substrates. ${ }^{10}$ Traumatic brain injury induces rapid and sustained $\mathrm{iCa}^{2+}$ elevations and calpain activation. ${ }^{10,11}$ Blocking calpain activity in TBI models reduces tissue loss. ${ }^{12}$ Increased $\mathrm{iCa}^{2+}$ also overwhelms mitochondria resulting in oxidative stress, mitochondrial permeability transition pore (MPTP) opening and cytochrome c release. ${ }^{13}$
This activates the intrinsic pathway (capase-9 dependent). ${ }^{14}$ Apoptotic cell death has been characterized after TBI. ${ }^{14,15}$ Therapies that block executioner caspases reduce tissue loss and improve outcome. ${ }^{16,17}$

\section{Additional Excitotoxic Death Pathways}

Necroptosis (programmed necrosis) is regulated by receptorinteracting serine/threonine-protein kinase (RIPK1/3) and mixed lineage kinase domain-like. ${ }^{18}$ Necroptosis is induced by co-incubation of tumor necrosis factor $\alpha$ (TNF $\alpha$ ) with ZVAD-FMK (a pan caspase inhibitor). Alone, TNF $\alpha$ stimulates the extrinsic cell death receptor-mediated apoptotic pathway (caspase-8 dependent). Caspase-8 cleaves and destroys RIPK preventing its activation. ${ }^{19}$ The addition of Z-VAD during TNF $\alpha$ - induced apoptosis in neurons stabilizes RIPK1/3 activating necroptosis. ${ }^{20}$ The necroptotic inhibitor necrostatin-1 inhibits neuronal death after TBI. ${ }^{21}$ However, excitotoxicity induces necroptosis in cultured neurons, but accounts for a fraction of the cell death. ${ }^{22}$ Autophagy is a homeostatic mechanism that regulates catabolism of damaged organelles (macroautophagy). Loss of autophagy may contribute to neurodegenerative disease, ${ }^{23}$ whereas overactivation may promote cell death. There is marked upregulation of autophagy after TBI. ${ }^{24}$ Mice treated with the autophagy inhibitor 3-methyladenine show reduced neuronal death after TBI. ${ }^{25}$ However, autophagy may also be beneficial late after TBI by helping to "clean-up" injured brain. ${ }^{26}$ Microglia can also release glutamate, enhance excitoxicity, ${ }^{27}$ and promote inflammasome-mediated cell death (pyroptosis) linked to caspase-1. All of these cell death pathways are targets for TBI therapy.

\section{Antiexcitotoxic Therapy}

Excitotoxicity plays a key role in tissue damage after TBI. Vespa et al $^{28}$ reported early posttraumatic subclinical seizure activity and its deleterious effects after severe TBI. Most strategies to reduce excitotoxicity include averting $\mathrm{Ca}^{2+}$ accumulation, or inhibiting downstream death signaling (caspases/apoptosis or calpains/necrosis). Historically NMDARs have been key targets. Nonselective NMDAR antagonists like MK801 are neuroprotective in TBI models. However, they failed in clinical TBI due to psychosomatic side effects, inadvertent death of select brain regions (cingulate and retrosplenial cortex), and limited therapeutic window. ${ }^{5}$ Progress in NMDAR-mediated neurotransmission has revealed greater complexity then previously appreciated-and may better inform therapy. $\mathrm{N}$-Methyl-D-aspartate receptors consist of heterodimeric glutamate receptor (GluR) subunits including NR1, NR2A, and NR2B. NR2A containing NMDARs are enriched in the synapse (synaptic NMDARs). ${ }^{29}$ NR2B containing NMDARs are enriched at extrasynaptic sites (extrasynaptic NMDARs). ${ }^{29}$ Spatial distribution of NMDARs greatly affects excitotoxic signaling. Activation of synaptic NMDARs is neuroprotective. They increase nuclear $\mathrm{Ca}^{2+}$, activate CREB, BDNF, protein kinase $B$ (AKT), phosphorylated-JACOB (pJACOB), and upregulate antioxidants. ${ }^{30-33}$ In contrast, activation of extrasynaptic NMDARs by glutamate spillover after TBI has the opposite effect. Extrasynaptic 
NMDARs increase cytoplasmic $\mathrm{Ca}^{2+}$, inhibit CREB, AKT, p-JACOB, BDNF, active calpain, stimulate death-associated protein kinase (DAPK), and activate autophagy. ${ }^{30,32-35}$ Extrasynaptic NMDARs play a role in cell death in TBI. The selective NR2B antagonist Ro 25-6981 inhibits induction of autophagy after TBI. ${ }^{34}$ Stretch injury increases NR2B/NMDAR currents, which open AMPARs. That deleterious cascade is prevented by the NR2B antagonists Ro 25-6981 and memantine (a lipophilic form of amantadine). ${ }^{36}$ Memantine (Namenda) was tested in rodent TBI many years ago. ${ }^{37}$ Recently it was discovered to block extrasynaptic NMDARs while sparing synaptic NMDAR function. ${ }^{38}$ It is approved by the U.S. Food and Drug Administration (FDA) to treat dementia and has proved a more tolerable NMDAR antagonist than MK801. ${ }^{39}$ Memantine and other next-generation NR2B-selective antagonists deserve additional study. ${ }^{40}$

\section{Considerations for Chronic Recovery after Traumatic Brain Injury}

Long-term blockade of NMDARs may limit recovery of brain function. Even mTBI disturbs synaptic processes resulting in impaired network connectivity. ${ }^{41,42}$ Abnormal synaptic connectivity may reflect aberrant decreases in glutamatergic neurotransmission or overactivation of GABAergic inhibitory input. $^{43,44}$ Levetiracetam (Keppra; UCB, Brussels, Belgium) is often used to control seizures in severe TBI patients. ${ }^{45}$ Although the mechanisms of action are not fully understood they involve GABAergic activation and inhibition of presynaptic glutamate release. ${ }^{46,47}$ Cognition remains largely intact in patients on levetiracetam. ${ }^{48}$ It is curious to speculate if levetiracetam may help balance long-term excitatory/inhibitory disturbances in neurotransmission after TBI.Zou et a ${ }^{49}$ recently reported benefit from chronic treatment with levetiracetam after $\mathrm{CCI}$ in rats. Thus, one approach might be to use a potent NMDAR antagonist like memantine early after TBI, to block excitotoxicity and then transition to therapies that fine-tune glutamatergic activity during recovery such as levetiracetam. - Fig. 1 provides an overview of excitotoxicity and its link to the neuronal death pathways along with emerging therapies.

\section{Therapies Targeting Brain Edema}

Brain edema has been a TBI target for decades. It is identified and continuously monitored in patients with severe TBI by imaging, clinical examination, and intracranial pressure (ICP) monitoring. Cerebral edema is caused by two main mechanisms-cellular (traditionally called cytotoxic) and vasogenicresulting from a disturbance in the blood-brain barrier (BBB). There are no therapies in clinical practice designed to prevent edema, rather than simply to treat it once it has occurred. Treatments for brain edema are limited to the use of osmolar agents (mannitol, hypertonic saline), which aid in water removal, sedatives like barbiturates, which can lower the cerebral metabolic rate and reduce brain swelling (via a coupled reduction in cerebral blood volume), cerebrospinal fluid (CSF) drainage via a ventriculostomy, and craniectomy. These guidelines-based therapies are routinely used in severe TBI. $^{50,51}$ However, they have toxicities. For example, increasing serum sodium to $>170 \mathrm{mEq} / \mathrm{L}$ to manage refractory brain swelling after severe TBI caused an increased rate of acute renal failure, thrombocytopenia, and acute respiratory distress syndrome. ${ }^{52}$ Also, the decompressive craniectomy (DECRA) trial failed to show improved outcome in adults with severe TBI (although it decreased ICP). ${ }^{53}$ Some have thus even begun to question the use of ICP monitoring in patients with severe TBI; this remains controversial. ${ }^{54} \mathrm{~A}$ recent randomized controlled trial (RCT) by Chesnut et $\mathrm{al}^{55}$ showed that outcomes after severe TBI did not differ between patients managed with ICP monitoring versus clinical exam/imaging-although the use of therapies for brain swelling was similar or greater in the patients treated based on the clinical exam/imaging. In contrast, other recent clinical studies have shown that even short periods of increased ICP unfavorably affect outcome, ${ }^{56}$ and new preclinical work suggests that very modest levels of raised ICP $(<20 \mathrm{~mm} \mathrm{Hg})$ may be deleterious. ${ }^{57}$ Brain edema might even contribute to secondary damage in mTBI if astrocyte swelling at the cellular level compromises astrocyte function.

\section{Novel Pathways of Edema Formation}

New understandings of the molecular underpinnings of brain edema are revealing new targets and therapies. Laird et $\mathrm{al}^{58}$ outlined molecular events that could contribute to the development of brain edema after TBI ( - Fig. 2). After TBI, neuronal necrosis can induce release of the danger signal high-mobility box protein 1 (HMGB-1). HMGB-1 binds to toll-like receptor- 4 (TLR-4) on microglia and triggers interleukin-6- (IL-6-) mediated aquaporin-4 (AQP4) channel upregulation in astrocytes, mediating edema formation. AQP4 is a membrane channel that regulates water transport. ${ }^{59}$ Consistent with this hypothesis, IL-6 and HMGB- 1 are increased in human CSF after severe TBI. ${ }^{60,61}$ HMGB-1 is also linked to brain edema in TBI models. ${ }^{58}$ In addition to binding to TLR4, HMGB-1 interacts with the receptor for advanced glycation end product (RAGE); the RAGE pathway may play a role in vasogenic edema/breakdown of BBB, ${ }^{62}$ while TLR4 may mediate cellular edema. ${ }^{58}$ Cerebrospinal fluid levels of HMGB-1 correlate with unfavorable outcome after TBI. $^{61}$ More discussion of this pathway is provided later in this review. Finally, Simard et $\mathrm{al}^{63}$ reported that sulfonylurea receptor 1 (SUR1) contributes to the development of brain edema. SUR1 channels conduct monovalent cations, are upregulated after TBI, and function independent of $\mathrm{Na}^{+}-\mathrm{K}+$ ATPase activity. ${ }^{63}$

\section{Emerging Therapies to Prevent Brain Edema}

Effort has been directed at developing new therapies for brain edema in TBI. The anti-inflammatory drug glycyrrhizin inhibits HMGB-1 from binding to RAGE and prevents BBB breakdown and vasogenic edema. ${ }^{58,62}$ Similarly, Okuma et $\mathrm{al}^{64}$ reported a reduction of edema in a rodent model using an anti-HMGB1 monoclonal antibody. Edema could also be reduced by inhibiting TLR4 with VGX-1027, which is in clinical trials for inflammatory diseases. ${ }^{58}$ Other therapies targeting HMGB-1/TLR4 are discussed later. AQP4 is another edema target in TBI. Injection of small-interfering RNA targeting AQP4 reduced brain edema in rats ${ }^{65}$ and selective AQP4 


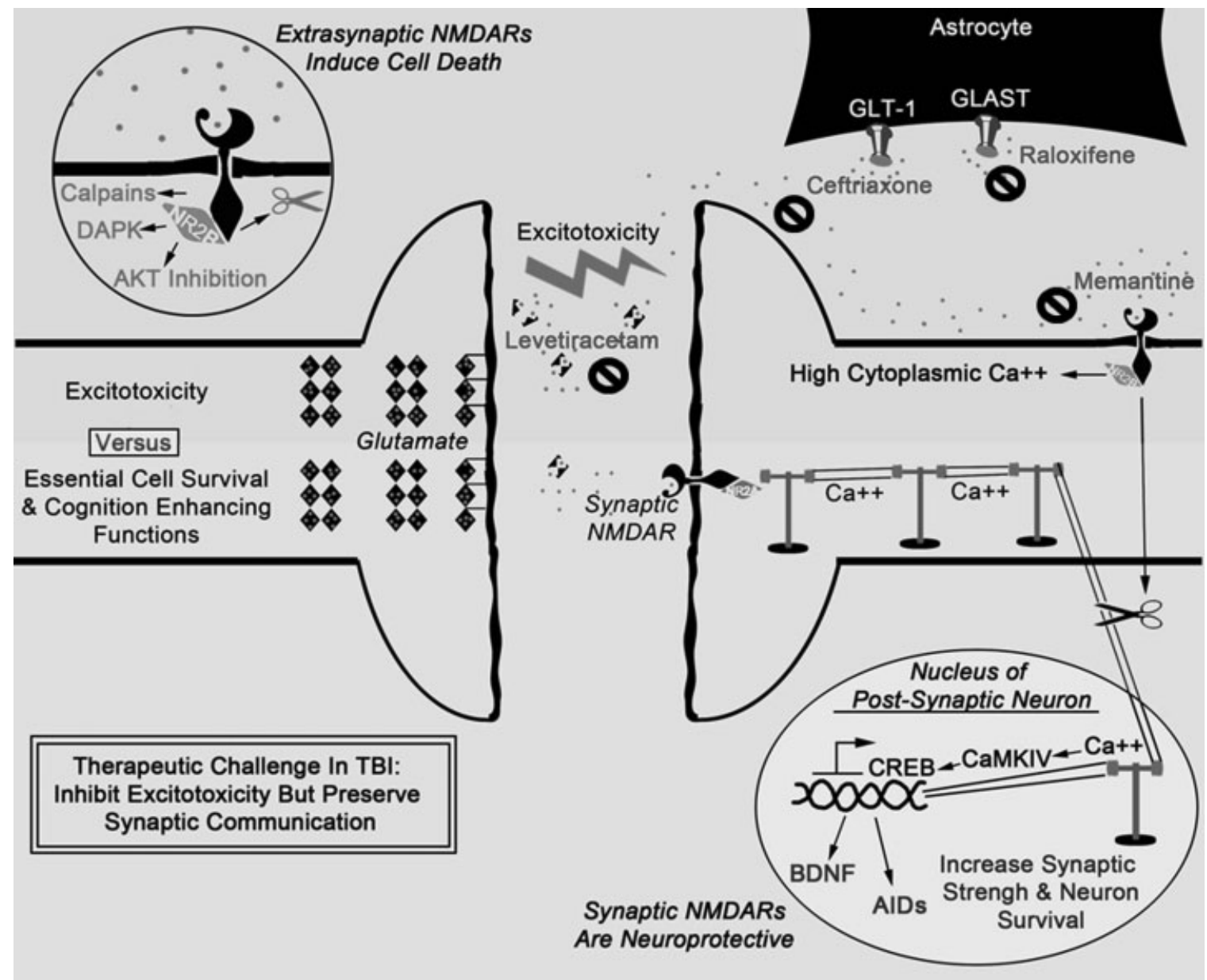

Fig. 1 Strategies to modulate traumatic brain injury- (TBI-) induced excitotoxicity while maintaining beneficial glutamatergic activation. Glutamate is an essential neurotransmitter in brain function. Normal release of glutamate from presynaptic neurons activates synaptic NMDARs (NR2A enriched) on postsynaptic neurons. Synaptic NMDAR activation promotes nuclear $\mathrm{CA}^{2+}$ influx. Synaptic-to-nuclear $\mathrm{CA}^{2+}$ communication transmits prosurvival signals (CaMKIV and CREB). The transcription factor CREB induces neuroprotective BNDF. Also, synaptic NMDAR activity stimulates expression of other protective AIDs. Traumatic brain injury alters $\mathrm{CA}^{2+}$ biochemistry to favor toxic cytoplasmic signaling. Extracellular glutamate activates distal extrasynaptic NMDARs (NR2B enriched). Extrasynaptic NMDARs promote cell death (top-left). They oppose synaptic NMDAR/CREB prosurvival responses and activate calpains and DAPK, and inhibit AKT survival signaling. Drugs approved by the U.S. Food and Drug Administration targeting excitotoxicity include (identified by $\varnothing$ ): (1) Memantine- blocks extrasynaptic NMDAR, (2) ceftriaxone and raloxifeneincreases expression of glutamate uptake transporters in astrocytes, and (3) levetiracetam-may inhibit high presynaptic glutamate release by modulating inhibitory GABAergic input to excitatory neurons. ALS, amyotrophic lateral sclerosis; CBF, cerebral blood flow; CTE, chronic traumatic encephalopathy; NMDAR, N-methyl-D-aspartate receptor; GluN2A/NR2A, glutamate N2A subunit; GluN2B/NR2B, glutamate N2B subunit; CREB, CAMP response element binding protein; GLT-1, glial glutamate transporter 1; GLAST, glutamate/aspirate transporter; AKT, protein kinase B; DAPK, death-associated protein kinase; BDNF, brain-derived neurotrophic factor; AID, activity-regulated inhibitor of death; $\mathrm{CaMK} \mathrm{CA}^{2+}$ I calmodulin dependent protein kinase.

antagonists are in development (personal communication, Marc Pelletier). The SUR1 receptor blocker glibenclamide (Glyburide) is another a promising therapy that reduces edema in TBI models. ${ }^{66}$ It is in a phase II clinical trial (NCT01132703) in TBI. These new agents give hope for improved management of brain edema. Studies in preclinical models are also needed to determine if reducing edema blunts secondary injury independent of ICP or reduced CBF, including studies in mTBI.

\section{Mitochondrial Targeting Therapies and Oxidative Stress}

Mitochondria have important functions ranging from generation of ATP to production of reactive oxygen species (ROS), which are important in the regulation of life and death decisions in cells. ${ }^{67}$ Dysfunctional mitochondria can also generate inflammatory and vasoactive mediators. ${ }^{68}$ Timely elimination of dysfunctional mitochondria via macroautophagy is essential particularly in postmitotic cells such as neurons. ${ }^{69}$ Mitochondrial dysfunction has been reported in experimental models and humans after $\mathrm{TBI}^{70-73}$ and is a robust target because alterations in mitochondrial function persist days after injury. ${ }^{74}$

\section{Role of Oxidative Stress in Traumatic Brain Injury} Oxidative stress plays a key role after $\mathrm{TBI}^{75}{ }^{7}$ It is classically described as a misbalance between the generation of free radicals and the body's ability to detoxify them. ${ }^{76}$ However, this definition fails to describe the essential roles free radicals 


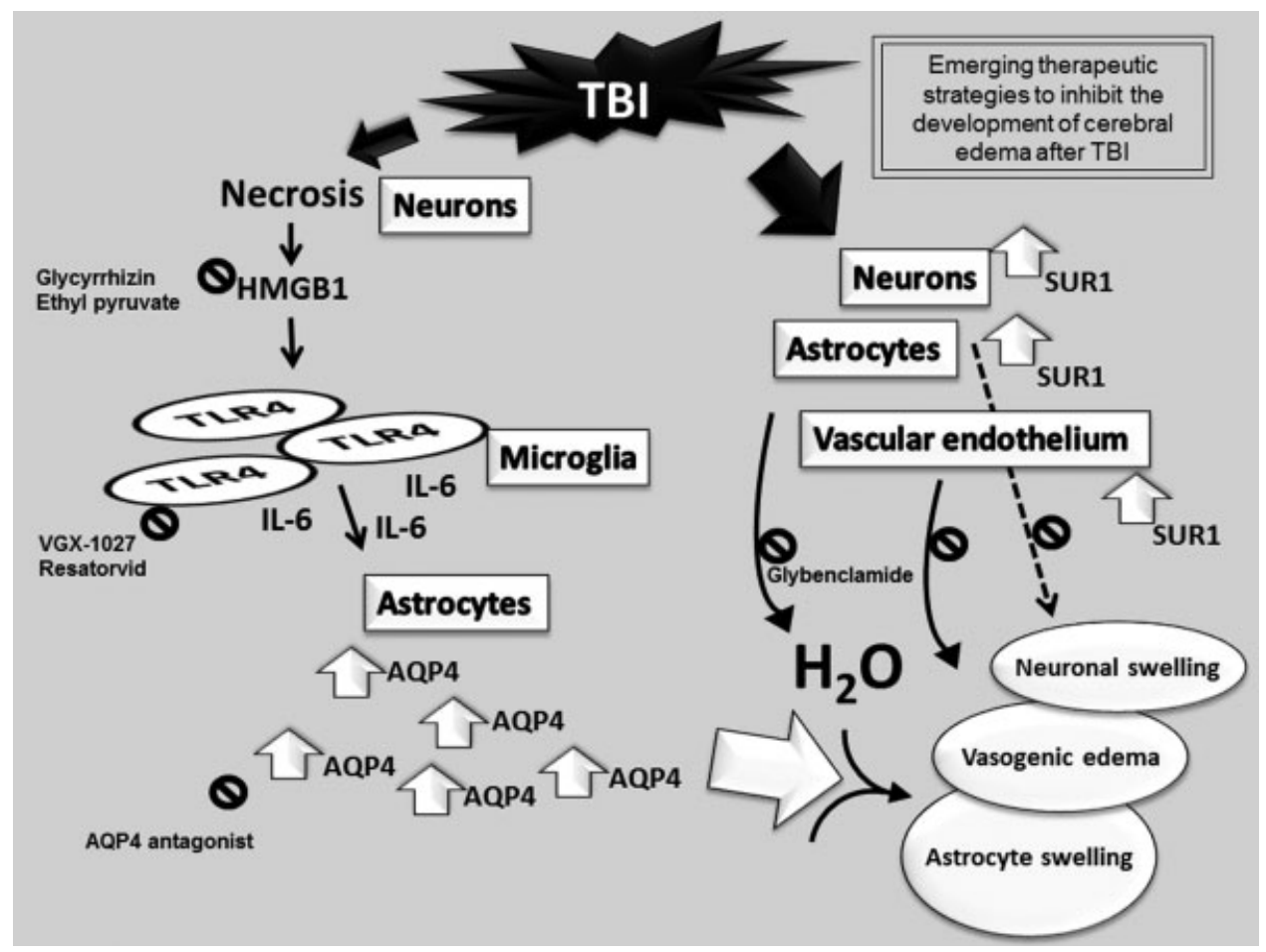

Fig. 2 Emerging therapies to inhibit the development of brain edema after traumatic brain injury (TBI). On the left, the novel molecular pathway of brain edema formation proposed by Laird et al, ${ }^{58}$ which hypothesizes that in areas of necrosis, HMGB1 release from neurons binds to TLR4 receptors on microglia and leads to elaboration of IL-6. IL-6 triggers upregulation of AQP4 water channels in astrocytes with water uptake across the blood-brain barrier and astrocyte swelling. On the right, a second pathway involves upregulation of the SUR 1 channel on neurons, astrocytes, and cerebrovascular endothelium. This monovalent cation channel is normally absent but is upregulated after TBI. Emerging therapies targeting both pathways (identified by Ø). For the HMGB1-TLR4 cascade (left), potential therapies include (1) the HMGB1 binding agent glycyrrhizin or release inhibitor ethyl pyruvate, (2) inhibitors of TLR4 signaling (VGX-1027 or resatorvid), or (3) AQP4 antagonists. The prototype therapy targeting the SUR1 channel pathway (right) is glibenclamide. HMGB-1, high-mobility box protein 1; TLR4, toll-like receptor-4; IL-6, interleukin-6; AQP4, aquaporin-4; SUR1, sulfonylurea receptor 1.

play in normal neuronal function, such as long-term potentiation. ${ }^{77}$ A more contemporary definition, "disruption of redox signaling and control," recognizes the compartmentalized nature of these events. ${ }^{78}$ For a thorough evaluation of oxidative stress, a battery of studies, including (1) assessment of generation of free radicals; (2) quantification of oxidation products of lipids, proteins, and DNA; and (3) evaluation of radical scavenging capacity, should be performed. All of these components of oxidative stress occur after experimental and clinical TBI. ${ }^{79-83}$ Several sacrificial antioxidants and free radical scavengers have been explored in TBI, such as PEGSOD, tirilazad, and edaravone. ${ }^{84-86}$ Although they have shown efficacy in TBI models, clinical trials failed to confirm efficacy ${ }^{87,88}$ The limitations of general antioxidant strategies include narrow therapeutic window, inability to cross the $\mathrm{BBB}$, and lack of targeting of the specific causes of oxidative stress. Without a targeted approach, the use of sacrificial antioxidants and free radical scavengers will fail.

\section{Mitochondrial Failure after Traumatic Brain Injury}

Mitochondria are a major intracellular source of ROS with production of superoxide and its dismutation product hydrogen peroxide. ${ }^{89}$ Other sources of oxidative stress after TBI include NADPH oxidase, nitric oxide (NO) synthases, xanthine oxidase, and transition metals, which can be released by hemorrhage. ${ }^{90,91}$ Underlying mechanisms of increased production of ROS by mitochondria include dysfunction of electron transport ${ }^{92}$ and impairment in $\mathrm{Ca}^{2+}$ buffering. ${ }^{93}$ Mitochondria are also targets of ROS, which can promote MPTP opening, leading to apoptosis. ${ }^{94}$ Mitochondrial DNA, which encodes elements for electron transport, is also a target for free radical damage. ${ }^{95}$ Thus, oxidative stress can impair mitochondrial function, which in turn generates more oxidative stress in a vicious cycle.

\section{Targeting Mitochondrial after Traumatic Brain Injury}

Several strategies have been designed to combat mitochondrial dysfunction, including alternative fuels and MPTP inhibitors. ${ }^{96,97}$ Preliminary studies in adults describe the safety of cyclosporine, a MPTP inhibitor, when given after severe TBI. ${ }^{98}$ These strategies target different components of mitochondrial dysfunction, but fail to localize into mitochondria. Recently small molecules have been discovered ${ }^{99}$ that can selectively accumulate in mitochondria and bind targets in the organelle to exert their effects. Several strategies have been used, including (1) conjugation to lipophilic cations such as triphenylphosphonium that take advantage of negative membrane potential of mitochondria, ${ }^{99}$ and (2) binding to a specific mitochondrial target such as cardiolipin (CL), a phospholipid exclusively found in the inner mitochondrial 
membrane. ${ }^{67}$ Both strategies are effective at delivering therapies into mitochondria. Compounds in the first category have not been tested in TBI. One of them, Mito-Q (a ubiquinone moiety linked to triphenyl-phosphonium), was used in recent human trials in Parkinson disease and hepatitis $C^{100}$ Compounds in the second category include Szeto-Schiller (SS) peptides. ${ }^{101}$ Their uptake into mitochondria is thought to be independent of membrane potential, with a high affinity binding to inner membrane. ${ }^{101}$ They contain four alternating aromatic amino acids and some have antioxidant activity. One of these peptides, SS-31, protects mitochondria, accelerates ATP recovery, and reduces infarct size in the heart. ${ }^{101}$ Another class of compounds in the second category promising for TBI are the hemigramicidin-nitroxides (GS-nitroxide), inspired by the shared ancestry between mitochondria and bacteria, taking advantage of chemical moieties used in antibacterial agents (the antibiotic gramicidin S) with high affinity for the inner membrane. ${ }^{102}$ One GS-nitroxide, XJB-5131 , was shown to partition almost exclusively into neuronal mitochondria in vitro, penetrate the BBB, prevent TBI-induced $\mathrm{CL}$ oxidation and caspase activation, and improve lesion volume and neurocognitive outcome after TBI. ${ }^{70}$ This is an exciting targeted strategy for TBI.

In summary, there is promising experimental success in application of mitochondria-targeted redox regulators in treatment of TBI, and these approaches deserve significant future efforts.

\section{Therapies Targeting Neuroinflammation}

Evidence suggests the inflammatory response, including cytokines, chemokines, microglial activation, and recruitment of circulating leukocytes, mediates secondary injury and/or repair after TBI. Traumatic brain injury causes the release of endogenous danger signals (i.e., extracellular ATP and HMGB-1), ${ }^{58,61}$ which bind to pattern recognition receptors such as TLR4 on neurons and glia to activate the immune response. Activated microglia undergo a phenotypic shift from an anti-inflammatory (M2) state to a proinflammatory and procytotoxic (M1) state. M1 microglia proliferate and migrate to the injury site and (1) form a barrier between damaged and healthy tissue, ${ }^{103}(2)$ increase expression of proinflammatory cytokines such as TNF $\alpha^{104}$ and IL-1 $\beta,{ }^{105}$ and (3) release ROS and reactive nitrogen species. Chronic microglial activation develops and may mediate chronic traumatic encephalopathy (CTE) and neurodegenerative diseases. ${ }^{106}$

\section{Dual Role of Inflammation in TBI}

Studies of the role of TNF $\alpha$ after TBI reveal the dual effects of inflammation in secondary injury and repair. Scherbel et al ${ }^{107}$ using a TNF KO mouse reported evidence of early neuroprotection in the KO at 48 hour; however, TNF KO mice had persistent motor deficits and more tissue loss at 4 weeks compared with wild-type. Balancing neurotoxicity with repair must be considered for therapies that modulate inflammation. Preclinical work with thalidomide analogs (TNFo synthesis inhibitor) and etanercept (fusion protein that binds to and inhibits TNF $\alpha$ ) have shown benefit early after TBI. ${ }^{108,109}$

\section{HMGB-1/TLR4 Pathway Inhibition}

HMGB1/TLR4 pathway inhibitors were previously discussed. They also block secondary injury due to immune activation. Ethyl pyruvate, an inhibitor of HMGB1 secretion, and resatorvid, a small molecule inhibitor of TLR4, improved outcome and reduced levels of TNF $\alpha$ and IL-1 $\beta$ in rodent TBI models. ${ }^{110,111}$ These drugs have not yet been evaluated in clinical trials for TBI.

\section{Other Anti-Inflammatory Agents}

Minocycline, a lipophilic tetracycline antibiotic with several proposed mechanisms of action, including inhibition of microglial activation, reduces IL- $1 \beta$ production, lesion volume, and functional deficits in TBI models. ${ }^{112} \mathrm{~A}$ phase 1 clinical trial of minocycline in TBI is recruiting patients. IL-1 $\beta$ antagonism via intraventricular injection of anti-IL-1 $\beta$ antibody ${ }^{113}$ and transgenic overexpression of IL-1 receptor antagonist (IL-1ra) ${ }^{114}$ reduced lesion volume and improved outcomes in TBI models. A recent phase 2 trial in adults with severe $\mathrm{TBI}^{115}$ randomized 20 patients to receive $100-\mathrm{mg}$ recombinant human IL-1ra (Anakinra) for 5 days, an FDA-approved dose for rheumatoid arthritis. Adverse events did not differ in treatment and control groups. Cerebral microdialysis showed increased levels of IL-1ra with treatment and a shift in the cytokine/chemokine profile. HMG-CoA reductase inhibitors (statins) have several proposed mechanisms of action after TBI (antiapoptotic, antioxidant, increase $\mathrm{CBF}$, and neurogenesis); however, the primary mechanism is likely anti-inflammatory. Two clinical studies of statins have been conducted-a RCT of rosuvastatin in 20 adults with TBI that showed improved memory with treatment, ${ }^{116}$ and a retrospective study showing a $76 \%$ relative risk reduction for mortality in patients treated with statins before injury. ${ }^{117}$ Larger RCTs are needed.

\section{Promoting Inflammation-Mediated Regeneration}

Another approach is to promote shifting microglia from the M1 to the M2 phenotype. Currently under investigation for treating multiple sclerosis, ${ }^{118}$ therapies such as glatiramer acetate, interferon- $\beta$, or dimethyl fumarate may promote the beneficial aspects of neuroinflammation-neurogenesis and repair-while reducing cytotoxic mediators. A similar approach is being adapted from spinal cord injury research with the use of "pro-inflammatory" therapy: G-CSF alone ${ }^{119}$ or in combination with mesenchymal stem cells. ${ }^{120}$ These therapies may also be useful late in the course of the disease to mitigate CTE. ${ }^{121}$

\section{Therapies Targeting Traumatic Axonal Injury}

Therapies targeting traumatic axonal injury (TAI) is a prominent feature of TBI and represents a vital target across the spectrum of injury severity. In classic studies, Povlishock $^{122,123}$ showed that TAI is a fundamental component of secondary injury after TBI and thus a key therapeutic target. Progression of TAI involves TBI-induced dysregulation of $\mathrm{Na}^{+}$ channels, in turn causing increased $\mathrm{Ca}^{2+}$ influx into axons, 
calpain activation with loss of microtubules, neurofilament impaction with impaired axoplasmic transport, ${ }^{124}$ and mitochondrial failure with permeability transition pore opening and oxidative stress. ${ }^{125}$ The aforementioned novel strategies targeting mitochondrial failure may be particularly efficacious in TAI. Smith et $\mathrm{al}^{124}$ recently identified categories of therapies for TAI based on work in TBI models: (1) cytoskeleton stabilization, (2) ion homeostasis, (3) protease inhibition, (4) mitochondrial protection, (5) mild hypothermia, and (6) other therapies. We will review and update those categories (-Fig. $\mathbf{3}$ ).

\section{Cytoskeleton Stabilization}

Loss of microtubule function devastates axonal transport. Unfortunately, data are limited on approaches to block this mechanism. The chemotherapeutic drug Taxol can inhibit chemical depolymerization of microtubules during stretch. $^{126}$ Taxol has not been tested in TBI in vivo, but recently produced axonal preservation after spinal cord injury in rats. ${ }^{127}$

\section{Ion Homeostasis}

There has also been limited work targeting $\mathrm{Ca}^{2+}$ accumulation linked to TAI. Rather, focus has been on downstream signaling cascades such as calpain activation. Therapies targeting major breaches in membrane disruption such as Kollidon VA64 show promise in TBI models. ${ }^{128}$

\section{Protease Inhibition}

Beneficial effects of calpain inhibition on TAI have been shown in rodent TBI models for over a decade, including use of MDL28170, AK295, and SJA-6017. ${ }^{124,129}$ However, lack of brain bioavailability and target specificity have limited the development of calpain inhibitors. Recent studies have suggested that citicoline suppresses calpain activation after TBI. However, the failed COBRIT clinical trial with citicoline argues against this agent. ${ }^{130}$ Given the evidence supporting a role for calpain in TAI, it is disappointing that additional calpain inhibitors are not available.

\section{Mitochondrial Protection}

Mitochondrial failure may worsen $\mathrm{Ca}^{2+}$ overload and exacerbate TAI. Preclinical work ${ }^{125}$ has shown benefit from cyclosporine A (CsA) on TAI. Inhibition of MPTP opening is suggested as the mechanism for this effect. However, clinical studies with CsA have been equivocal. ${ }^{3}$ The aforementioned GS-nitroxides $^{70}$ or $\mathrm{N}$-acetyl cysteine (NAC) amide $\mathrm{ar}^{131}$ are logical candidates to study.

\section{Hypothermia}

Preclinical work shows that mild hypothermia can attenuate TAI. ${ }^{129}$ Sadly clinical trials in TBI have failed. ${ }^{132}$ Surprisingly, hypothermia failed to attenuate the increase in CSF levels of myelin basic protein after severe TBI in children. ${ }^{133}$ Mild hypothermia was recently shown to markedly attenuate TAI

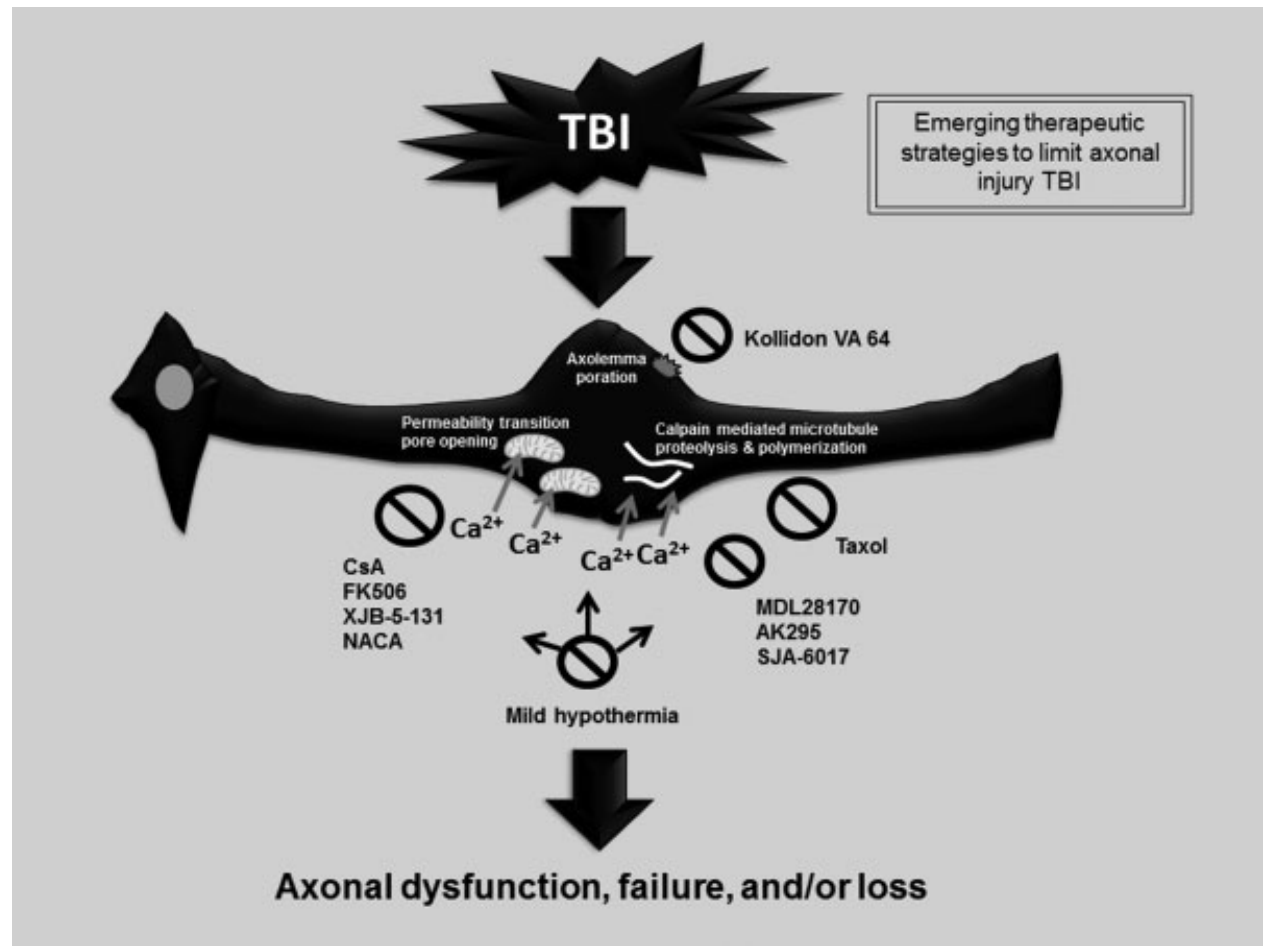

Fig. 3 Emerging therapies to limit traumatic axonal injury (TAI) after traumatic brain injury (TBI). ${ }^{124}$ Cellular and molecular events in the TAI cascade include $\mathrm{Ca}^{2+}$ accumulation with calpain activation and resultant microtubule proteolysis, MPTP opening, and oxidative stress. Direct membrane poration can also mediate injury. Emerging therapies (identified by $\emptyset$ ) include calpain antagonists (MDL28170, AK295, SJA-6017), and taxol, which may prevents microtubule polymerization. Therapies targeting mitochondria include CsA that blocks MPTP, FK506 that may target calcineurin induced translocation of BAD, and XJB-5-131 and NACA that target oxidative stress in mitochondria. Kolloidan VA64 may directly reseal membranes. Mild hypothermia may reduce TAI by multiple mechanisms. CsA ,Cyclosporin A; NACA, N-acetyl cysteine amide. 
after repetitive mTBI in rats. ${ }^{134}$ Mild hypothermia deserves exploration in mTBI.

\section{Other}

In addition to CsA, the calcineurin inhibitor FK506 has been shown to reduce TAI, particularly in unmyelinated axons. ${ }^{135}$ It is unclear whether this is independent of effects on mitochondria. ${ }^{124}$ Therapies targeting oxidative damage have also been suggested to reduce $\mathrm{TAI}^{134}$-these were discussed previously.

\section{Therapies Targeting Cerebral Blood Flow Dysregulation and Ischemia}

After TBI, CBF dysregulation develops and may contribute to secondary damage. In mTBI, vascular dysregulation could mediate vulnerability to a second hit. ${ }^{136}$ Cerebral blood flow is often reduced early after severe TBI. ${ }^{137}$ This may result from a coupled reduction in brain activity, but can be pathologic during excitation. Cerebrovascular resistance (CVR) is controlled at the macro- and microvascular level. At the microvascular level, it is coupled to brain metabolic activity. Recently, Hall et $\mathrm{al}^{138}$ showed that pericytes positioned around brain capillaries mediate dilation that produces a much greater change in $\mathrm{CBF}(19 \%$ vs. $3 \%$ ) than dilation of arteries aloneimplicating pericyte-mediated dilation as the major contributor to changes in CBF. Key metabolites identified included the vasodilators nitric oxide $(\mathrm{NO})$ and prostaglandin-E2 $\left(\mathrm{PGE}_{2}\right)$ and the vasoconstrictor 20-hydroxyeicosatertraenoic acid (20HETE). They implicated the relative production of these metabolites in regulating pericyte dilation and thus CBF. The potent vasoconstrictor endothelin-1 (ET-1) may also contribute to CBF dysregulation after TBI.

\section{Modulating Nitric Oxide}

Nitric oxide is a potent vasodilator and may be useful to treat ischemia after TBI. Conversely, NO at high levels can be converted to peroxynitrite, which can worsen damage. This paradox has yielded interventions that augment NO delivery or block NO production after TBI. The primary clinical strategy to increase NO delivery is with inhaled NO. Inhaled NO is FDA-approved for neonatal respiratory failure. Studies suggest that inhaled NO improves collateral circulation and outcomes in TBI models. ${ }^{139}$ However, in newborn piglets, the NO donor sodium nitroprusside did not prevent impaired autoregulation during hypotension after TBI, implying that NO augmentation may only be beneficial in normotensive states. ${ }^{140}$ This is important, given that NO augmentation can produce hypotension that may mitigate benefit. Whether inhaled NO is a viable approach remains to be determined. Nitric oxide synthase inhibitors are also being explored in TBI. A phase II placebo controlled trial with the NO synthase inhibitor VAS 203 was just completed in 32 adults with TBI (NOSTRA; NCT 02012582). It suggested improved outcomes, but renal injury was a concern. It is unknown if NO augmentation or inhibition is preferred. A targeted approach to NO delivery to maximize microvascular affects coupled with selective inhibition of inducible NOS (iNOS) to prevent nitro- sative stress might be considered. However, sustained inhibition of iNOS may be deleterious given that iNOS KO mice exhibit marked impairments in cognitive outcome. ${ }^{141}$

\section{Modulating ET-1}

In TBI, ET-1 levels in CSF are increased and linked to unfavorable outcomes. ${ }^{142}$ However, in a phase $2 \mathrm{~b}$ trial, the ET receptor $A$ antagonist clazosentan failed to improve outcomes after subarachnoid hemorrhage (SAH). ${ }^{143}$ New ET-1 antagonists remain to be tested in TBI.

\section{Statins}

HMG-CoA reductase inhibitors (statins) are used for cholesterol reduction. As discussed, they have anti-inflammatory effects, but also upregulate eNOS and increase NO production, leading to improved capillary patency. ${ }^{144} \mathrm{Clinical}$ trials with statins suggest a potential benefit on outcome in TBI, although the role of effects on CBF is unclear. ${ }^{145}$ In stroke, an RCT of lovastatin is in phase 2 trials (NeuSTART, NCT01976936). ${ }^{146}$ The optimal choice of statin and dosing for BBB penetration also remain unclear. Results from larger RCTs in TBI are needed to define the utility of these agents in TBI.

\section{Cytochrome P450 Metabolites}

Cytochrome P450 produces two classes of arachidonic acid metabolites with opposing microvascular effects. Hydroxylation produces 20-HETE, a potent vasoconstrictor, while epoxidation produces epoxyeicosatrienoic acids (EETs), which are vasodilatory. Both 20-HETE and EETs are autoregulatory mediators. Inhibition of 20-HETE formation by NO is an essential pathway of PGE2-mediated pericyte dilation. ${ }^{138}$ Inhibition of 20-HETE formation or prevention of EET metabolism can reduce lesion volume in stroke and SAH models. ${ }^{147,148}$ 20-HETE is involved in reduced CBF in cortical spreading depression ${ }^{149}$ - a secondary injury mechanism implicated in TBI. ${ }^{150}$ Thus, cytochrome P450 arachidonic acid metabolites affect CBF after TBI. It remains to be determined whether targeting these pathways can improve outcome after TBI.

\section{Enhancing Oxygen Delivery}

Another approach to reduce ischemic damage is to improve oxygen delivery despite CBF reductions-such as with perfluorocarbon-enhanced oxygen delivery. A safety/efficacy RCT is evaluating the perfluorocarbon Oxycyte (STOP-TBI; NCT00908063). Mild hypothermia has also been shown to reduce $\mathrm{CBF}$ dysregulation after TBI. ${ }^{151}$ This includes benefit injury in repetitive mTBI. ${ }^{134}$

In summary, an emerging area TBI is mitigating microvascular dysregulation. These approaches and others deserve further investigation in TBI, including testing in mTBI.

\section{Cognitive Enhancement}

Many rehabilitation strategies have been used to enhance cognitive function after TBI. Some of the most effective preclinical rehabilitative strategies in TBI have been neurostimulant pharmacotherapies, and as discussed below, 
successful clinical translation of this approach in an RCT was recently acheived. ${ }^{2}$ Thus, we will focus on these agents as emerging TBI therapies.

\section{Catecholamine Agonists}

Catecholamine agonists promote functional recovery after TBI. This was confirmed in weight drop cortical contusion or ablation models in rats and/or cats. ${ }^{151-154}$ Because norepinephrine antagonists block or reinstate deficits, the noradrenergic system has been implicated. However, clinical ${ }^{155,156}$ and experimental ${ }^{157,158}$ research shows that the dopamine (DA) system is also involved in both injury and rehabilitative processes. Methylphenidate, a psychostimulant and DA transporter inhibitor, exhibits pharmacological properties similar to amphetamine, but without undesirable sympathomimetic effects. In a study assessing motor function after sensorimotor cortex injury in rats, a single dose of methylphenidate followed by symptom relevant experience (beam walking) enhanced beam-walk ability. ${ }^{154}$ This work supports the importance of an interaction between pharmacotherapy and symptom-relevant experience (rehabilitation) in promoting functional recovery after TBI. Moreover, daily treatment with methylphenidate beginning as late as 24 hours after $\mathrm{CCI}$ in rats revealed less spatial memory deficits versus controls. ${ }^{159}$ Wagner et al ${ }^{160}$ has showed that methylphenidate exhibits some restorative capacity for striatal DA neurotransmission after experimental TBI; their additional work suggests potential sex differences in methylphenidate treatment effects and dosing for male versus female rats. ${ }^{161}$

\section{Amantadine-A Translational Success}

With success in preclinical studies as well as phase 2 and phase 3 clinical trials, amantadine (Symmetrel; Endo Pharmaceuticals, Malvern, PA) is a promising drug for TBI rehabilitation. 2,162 Daily treatment with amantadine (for $20 \mathrm{~d}$ ) after $\mathrm{CCI}$ in rats revealed improvements in spatial memory performance deficits versus saline-treated counterparts. ${ }^{163}$ Higher doses also benefit cognition after fluid percussion. ${ }^{164}$ Clinically, amantadine accelerates the rate of functional recovery in vegetative or minimally conscious patients during the subacute phase after $\mathrm{TBI}^{2}{ }^{2}$ It exerts its effects by increasing extracellular DA by blocking reuptake and by facilitating synthesis. ${ }^{165,166}$ In addition to its presynaptic actions, amantadine increases the density of postsynaptic DA receptors ${ }^{166}$ or alters their conformation, which may be clinically important. ${ }^{167}$ Because the mechanism of action of amantadine differs from other DA-releasing drugs, ${ }^{168}$ it is likely that the dopaminergic effects of amantadine are a combination of presynaptic and postsynaptic effects. It also blunts NMDAR activation.

\section{Bromocriptine}

Delayed or chronic treatment with the D2 receptor agonist bromocriptine also improves the acquisition of spatial and working memory in rats after $\mathrm{CCl} .{ }^{169}$ Bromocriptine $(5 \mathrm{mg} / \mathrm{kg}$ ) has been shown to increase extracellular DA levels in rats, ${ }^{170}$ suggesting that enhanced presynaptic DA neurotransmission may have mediated the benefit at this dose. Bromocriptine also attenuated lipid peroxidation, suggesting antioxidant effects. ${ }^{169}$ Further support for dopaminergic activity in restoring functional recovery after TBI comes from a preclinical study showing that selegiline (L-deprenyl), which enhances the action of DA by inhibiting its main catabolic enzyme in brain, monoamine oxidase- $B$, improved cognitive outcome when given daily for 7 days after fluid percussion injury. ${ }^{171}$ Clinical studies showing benefits of DA augmentation after TBI also exist. $^{172,173}$

Thus enhancing catecholamine neurotransmission during the chronic postinjury phase may be a useful adjunct in ameliorating the neurobehavioral sequelae of TBI in humans. Additional studies are warranted.

\section{Augmenting Endogenous Neuroprotectants}

Evolution has provided several naturally occurring neuroprotective mechanisms. Perhaps the "low-hanging fruit" for increasing therapeutic options for TBI patients resides in augmenting the mechanisms that allowed the brain to evolve in the first place.

\section{Adenosine as an Archetype for Endogenous Neuroprotection}

Adenosine is released by tissue injury via several pathways. Breakdown of ATP is one source of adenosine in the injured brain (the traditional route). Recently, an alternative 2',3' cAMP pathway was discovered, and involves production of adenosine from mRNA breakdown via 2',3'cAMP. This latter pathway appears to play a major role after TBI. ${ }^{174}$ Adenosine acts on cell surface receptors (A1, A2A, A2B, and A3) and engages signal transduction that is neuroprotective in TBI. ${ }^{175}$ Activation of A1 receptors attenuates post-TBI excitotoxicity. Mice null for A1 receptors suffer lethal status epilepticus after $\mathrm{TBI},{ }^{176}$ and variants in the $\mathrm{A} 1$ receptor genes associate with posttraumatic seizures in TBI patients. ${ }^{177}$ Moreover, A1 receptor KO mice exhibit enhanced microglial proliferation after TBI. ${ }^{178}$ However, systemic effects of A1 agonists (bradycardia, hypotension) limit their use in TBI. A more effective strategy might be to enhance adenosine levels in the brain or increase A1 receptor numbers and/or signaling. One approach would be to upregulate enzymes that produce adenosine. For example, isoflurane increases activity of the adenosine-forming enzyme ecto-5'-nucleotidase (CD73) by stimulating release of microparticles, ${ }^{179}$ which may contribute to its neuroprotection. ${ }^{180}$ Another approach would be to administer chronically and prophylactically an A1 receptor blocker with a short half-life. This would upregulate A1 receptor numbers and signaling in the brain, yet post-TBI the antagonist would dissipate rapidly, leaving enhanced adenosine signaling at the time of greatest need. Improved outcomes are seen in TBI patients with caffeine (a short half-life adenosine receptor antagonist) in their CSF at the time of injury. ${ }^{181}$ Finally, adenosine kinase (ADK) is a key enzyme in the breakdown of adenosine. Adenosine kinase increases markedly in the astrocyte scar and limits adenosine availability chronically after TBI. ${ }^{182}$ Given the anticonvulsant effects of A1 receptors, blocking ADK or using other strategies to 
overexpress adenosine may represent a therapy for posttraumatic seizures. Huber et al $^{183}$ used grafts of adenosinereleasing fibroblasts to suppress seizures in rats. A1 receptor gene polymorphisms are strongly associated with posttraumatic seizures. ${ }^{177}$ Thus, it may be possible to use a personalized medicine approach to define patients who might benefit from adenosine augmentation therapy.

\section{Other Endogenous Neuroprotectants}

There are many other endogenous neuroprotectants emerging as therapies for TBI. Augmentation of trophic factors such as BDNF, or immediate early gene products such as HSP, could improve outcome after TBI. ${ }^{184}$ It was recently shown that remote preconditioning using tourniquet inflation/deflation may mediate benefit in ischemia/reperfusion via local elaboration of nitrite-which is converted to $\mathrm{NO}$ in regions of tissue hypoxia. ${ }^{185}$ Systemic nitrite therapy might yield similar effects. ${ }^{186}$ An endogenous neuroprotectant receiving attention in Parkinson disease is uric acid, which has antioxidant effects. $^{187}$ Finally, regulators of cold stress such as RNAbinding motif 3 (RBM3) stabilize mRNAs and may underlie benefit in hypothermia. ${ }^{188}$ New drugs are targeting RBMs. ${ }^{189}$

\section{Cellular Therapies}

Therapies designed to replenish cells lost after TBI may help improve outcome. Methodologies include supplementation of exogenous stem cells or therapies that enhance endogenous neurogenesis in the adult brain. Both approaches have promise based on studies in TBI models. New approaches are being used to enhance the regenerative capacities of these cellular therapies in hopes of developing interventions that can ultimately promote recovery in patients.

\section{Administration of Exogenous Cells}

Traumatic brain injury can be associated with loss of neurons and other cells in multiple brain regions. Administration of exogenous bone marrow stromal cells in rats, via intracrani$\mathrm{al}^{190}{ }^{19}$ intra-arterial, ${ }^{191}$ or intravenous delivery, ${ }^{192}$ results in a portion of transplanted cells migrating into the brain parenchyma, and is associated with improved motor function after TBI. ${ }^{190,193}$ Survival of stromal cells is associated with increased production of BDNF and nerve growth factor. ${ }^{192}$ In other studies, transplantation of neural stem cells ${ }^{194,195}$ and the coadministration of neural stem cells and olfactory ensheathing cells similarly improve motor performance after TBI. ${ }^{196}$ However, it is unclear whether the regenerative capacity of transplantation is dependent upon the incorporation of the exogenous cells, the production of soluble growth permissive factors, or their combination. Two studies provide evidence for complex dynamics between the contributions of exogenous cell survival and the release of soluble factors that promote regeneration after TBI. Intracranial administration of human bone marrow stromal cells in a collagen scaffold matrix enhances the survival of the stromal cells in the cortex and improves motor function compared with administration of stromal cells alone. ${ }^{52}$ Coadministration of the collagen scaffold also enhanced corticospinal tract sprouting in the denervated spinal cord, ${ }^{197}$ suggesting contributions from both the surviving stromal cells and soluble factors that promote regeneration after TBI. Tajiri et al ${ }^{198}$ studied soluble factors released from transplanted human adipose-derived stem cells that may play a role in recovery after TBI. Delivery of either the adipose-derived stem cells or conditioned media improved outcome in rats after TBI. However, knockdown of two long noncoding RNAs, important for cellular differentiation, blunted the recovery. These data indicate that regeneration can be enhanced with soluble factors in the absence of transplanted cells. They reveal the potential of transplantation approaches and highlight the complex dynamics between stem cells and growth permissive factors in promoting recovery.

\section{Enhancing the Generation and Survival of Newborn Cells}

Therapies that enhance the generation of newborn neurons are also attractive after TBI. Enhancement of neurogenesis after TBI with growth factors, neuroprotective agents, and hypothermia promotes cellular proliferation and increases the generation of newborn neurons in neurogenic regions of the injured brain. ${ }^{199-202}$ These studies have also shown that an enhancement of posttraumatic neurogenesis in the weeks after TBI is associated with improved neurobehavioral performance. Hippocampal immature neurons are particularly sensitive to brain injury in the days postinjury. ${ }^{202}$ Promoting survival of neural stem cells and immature neurons is a promising target to improve outcome. ${ }^{203}$ Blaya et al ${ }^{204}$ evaluated the efficacy of the neuroprotective agent P730-A20 to promote the survival of immature neurons, as this drug blocks apoptosis in immature neurons. Treatment with P730-A20 improved immature neuron density, increased the number of newly generated neurons, and improved cognitive performance. This highlights the promise of therapies promoting newborn neuron survival and incorporation into the injured brain.

\section{Clinical Trials of Cellular Therapy}

There are several clinical trials exploring cellular therapy in TBI. Recently a study addressing "Safety of Autologous Stem Cell Treatment for TBI in Children" (NCT00254722) was completed. The objective of that phase 1 study was to determine if bone marrow precursor cell harvest and autologous transplantation (within $36 \mathrm{~h}$ of injury and by intravenous route) is safe in children after TBI. The study was completed; a phase II trial is recruiting (NCT01851083). There is also an open label study of "Autologous Bone Marrow Mononuclear Cells in TBI" (NCT0202810), in which bone marrow-derived mononuclear cells are given intrathecally. That study is also recruiting.

\section{Combination Therapy}

Combination therapy is attractive to overcome translational challenges. Incomplete understanding of dose-response relationships and poor central nervous system (CNS) penetration of therapies are factors widely acknowledged to contribute to 
failed clinical trials. ${ }^{205-207}$ The heterogeneity of TBI and its complex pathophysiology suggest that it is unlikely that any single agent can address all of the secondary injury mechanisms. ${ }^{205}$ The success of combination therapies that enhance drug exposure or have complementary mechanisms of action in cancer and human immunodeficiency virus has further increased enthusiasm for this approach in TBI research.

\section{Emerging Combination Therapies}

In 2008, the NIH convened a workshop on multidrug combinations for TBI. The recommendation was to combine therapies with complementary targets and effects rather than focus on a single target with multiple therapies. ${ }^{207}$ Several combination therapies meeting this definition are being investigated. One of the most promising combines the antiinflammatory agent minocycline and the glutathione precursor NAC. Effects of minocycline were discussed previously. $\mathrm{N}$-acetyl cysteine is a precursor for synthesis of the antioxidant glutathione, impacts glutamatergic transmission, and despite poor CNS penetration improved outcomes in some TBI models and in blast-induced mTBI in humans. ${ }^{208-210}$ When given together, benefits of the combination exceed that of the single agents studied in CCI and mTBI models. $^{211,212} \mathrm{~N}$-acetyl cysteine is used in another combination therapy designed to improve drug exposure. Our group is testing coadministration of the FDA-approved organic acid transporter and multidrug resistance-associated protein inhibitor, probenecid, with NAC in preclinical and phase I pediatric studies (NCT01322009). The aim is to overcome membrane barriers, such as the $\mathrm{BBB}$, to synergistically improve NAC bioavailability and antioxidant reserves after TBI. Preclinical pharmacokinetic $(\mathrm{PK})$ data show that probenecid increases NAC brain penetration in juvenile rats two- to threefold as early as 1 hour after injury. ${ }^{213}$ Outcome studies are underway. Other combinations such as progesterone plus vitamin D are in early stages of preclinical investigation. ${ }^{214}$

Addressing Unique Challenges of Combination Therapy Interactions between therapies may alter PK (dose-concentration relationships) or pharmacodynamic (concentrationeffect relationships) properties of either therapy. They may be additive, synergistic, or antagonistic. Thus, studies using fullfactorial designs at multiple dosing levels are ideal. ${ }^{207}$ These data are used to identify combinations and sequences of therapies that achieve greater efficacy and lower toxicity than either therapy alone. Specific statistical approaches to identify synergism are advocated. ${ }^{215}$ Coadministered therapies should also be evaluated for physiochemical incompatibilities to ensure systemic bioavailability. As with single drugs, it is imperative to measure brain concentrations of therapies used in combination to optimize their potential for success.

\section{Therapies Targeting TBI Resuscitation in Polytrauma}

Traumatic brain injury is often accompanied by secondary insults (hypotension, hemorrhage, hypoxemia) that worsen outcome. ${ }^{216}$ However, given their complexity, clinical studies commonly exclude these patients, and few animal models have been developed to investigate therapies. Optimal resuscitation of the TBI patient with polytrauma continues to present unique challenges and remains understudied.

\section{Resuscitation Fluids}

The mainstay of resuscitation involves fluids: crystalloids, colloids, and/or blood products. Crystalloids are the initial therapy; however, large volumes are often needed, which can exacerbate brain edema. ${ }^{217}$ Colloids, given their improved ability at maintaining intravascular volumes, are attractive; however, in the SAFE study, TBI patients resuscitated with albumin had raised ICPs and greater mortality compared with saline-treated patients. ${ }^{218}$ Traumatic brain injury-induced BBB permeability may have allowed extravasation of albumin into brain-potentiating rebound brain edema. ${ }^{219}$ Thus, small molecule colloids may be problematic early after TBI. Blood products are not available for prehospital use.

\section{Emerging Resuscitation Agents}

Given the risk of exacerbation of brain edema with current resuscitation fluids, new therapies are being investigated, including novel, ultra-small-volume resuscitation agents. Polynitroxylated pegylated hemoglobin (PNPH) is one agent that may represent an out-of hospital bridge to transfusion. Polynitroxylated pegylated hemoglobin is a bovine-based hemoglobin that, in an effort to eliminate toxicity of cell-free hemoglobin, is covalently bonded with antioxidant nitroxide moieties and polyethylene glycol side chains. Polynitroxylated pegylated hemoglobin is being developed as a small-volume resuscitation solution. In a model of TBI plus hemorrhage, it dramatically reduced resuscitation fluid requirements compared with crystalloid. ${ }^{220,221}$ It also reduced ICP, brain edema, and neuronal death. ${ }^{220,221}$ Unlike conventional free hemoglobins, it has surprising in vitro neuroprotective effects. ${ }^{221}$ It is in preclinical development. Traditional resuscitation approaches focus on improving tissue perfusion by increasing circulating blood volume. An alternative might entail modification of microcirculatory blood flow. Drag-reducing polymers (DRPs) at nM levels markedly reduce the resistance of microvascular flow, improving tissue perfusion. 222,223 Drag-reducing polymers, such as long-chain polyethylene glycol $\left(\mathrm{kDa}>10^{6}\right)$, improve perfusion and reduce mortality in models of hemorrhagic shock. ${ }^{224}$ Drag-reducing polymers thus could maintain brain perfusion despite using a volume-limited resuscitation.

\section{Conventional Resuscitation Plus Antiedema Therapies}

Although volume-limiting resuscitation strategies hold promise in TBI, treatment with the aforementioned novel drugs targeting brain edema (Kollidon VA64, glibenclamide, AQP4 antagonists) could reduce the deleterious effects of resuscitation fluids on edema after TBI. Preclinical studies of these drugs are needed in models of TBI plus hemorrhage/ polytrauma. 


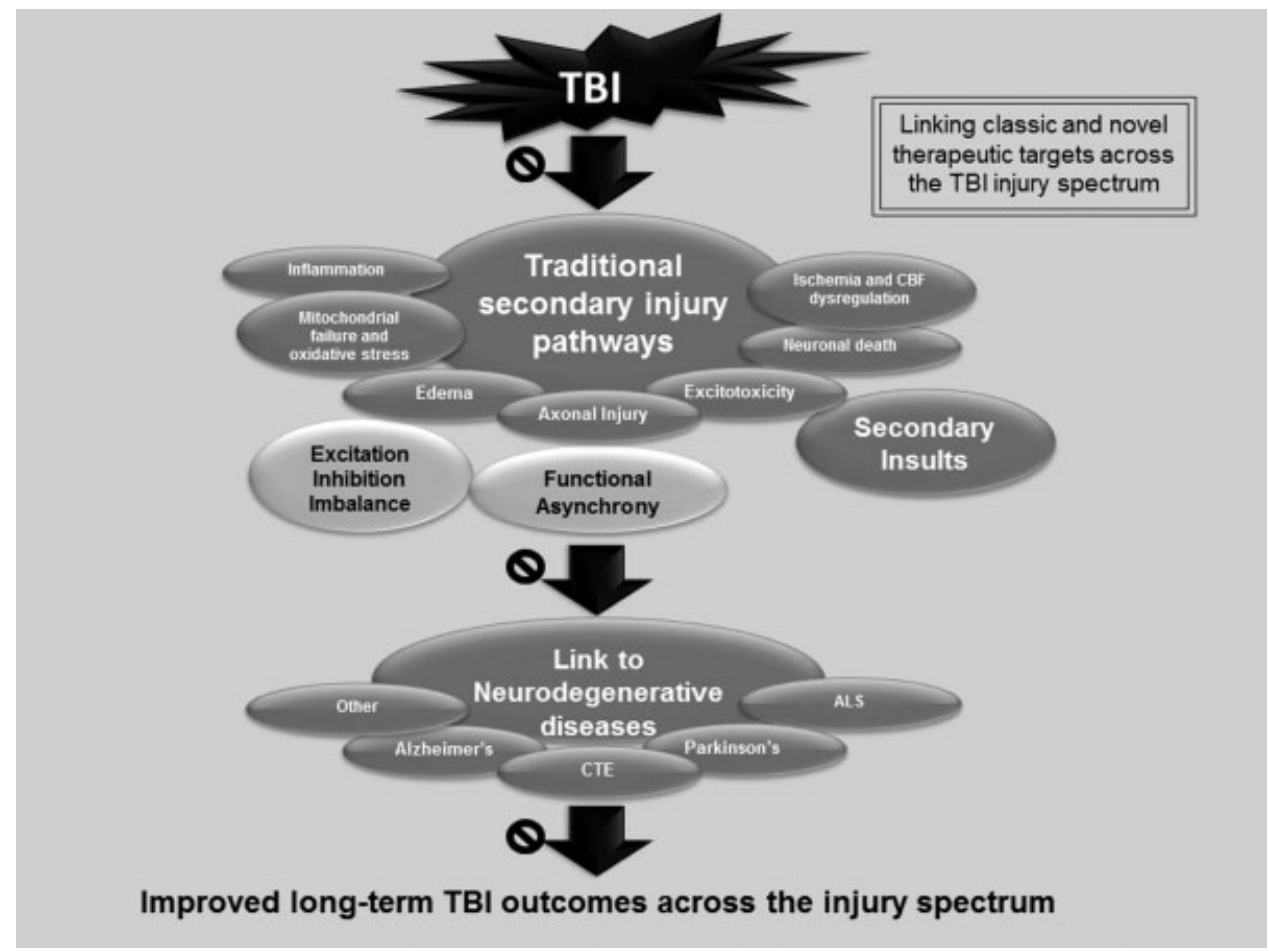

Fig. 4 A contemporary view of therapeutic targets across the spectrum of traumatic brain injury (TBI) from mild to severe includes classical secondary injury pathways along with novel mechanisms such as excitation inhibition imbalance and functional asynchrony that have come to the forefront in mild TBI. Therapies to embellish rehabilitation-based strategies to break the link between TBI and chronic neurodegenerative diseases such as chronic traumatic encephalopathy (CTE) are also needed. Therapies are identified by $\emptyset$. ALS, amyotrophic lateral sclerosis.

\section{Other Therapies}

Many more emerging therapies are on the horizon, including the use of transcranial low level laser, ${ }^{225}$ neutraceuticals, $^{226,227}$ lithium, ${ }^{228}$ modulating cell cycle ${ }^{229}$ and targeting microhemorrhage, ${ }^{230}$ among many others. This brief list illustrates the level of creativity in our dynamic research field.

\section{Conclusion}

This review is far from comprehensive. However, given our goal to address mechanism-based emerging therapies across the injury-severity spectrum, and from the field to rehabilitation, we chose to provide a "survey" across key mechanisms. There are many other promising agents worthy of investigation. We also believe that the recent surge in interest in mTBI may identify new targets in severe TBI-particularly given the fact that in patients with severe TBI, brain regions outside of areas of major disruptions are likely to be plagued by the pathomechanisms seen in mTBI. Thus, new investigations into therapies for $\mathrm{mTBI}$ may provide new opportunities for treatment of severe TBI. For example, emerging mechanisms in mTBI, such as disturbances in the balance between excitatory and inhibitory pathways or disturbances in synchronization, ${ }^{42,231}$ could be important in severe TBI-layered upon the classical injury paradigms (-Fig.4). Finally, to complement rehabilitation and cognitive enhancing therapies currently used chronically after TBI, new approaches to break the link between TBI and chronic neurodegenerative diseases including CTE are needed (-Fig. 4). The current golden age of TBI research thus represents a special opportunity for the development of breakthroughs in the field.

\section{Acknowledgments}

Supported by U.S. Army grants W81XWH-10-1-0623 (PMK) and W81XWH-14-2-0018 (PMK), NIH grants NS088145 (TJ), NS087978 (PMK, EKJ), and T32HD040686 (NF, EB, SC); and KL2-TR000146 from the NCATS as part of the Multidisciplinary Clinical Research Scholars Program (PE).

\section{References}

1 Robertson CS, Hannay HJ, Yamal JM, et al; Epo Severe TBI Trial Investigators. Effect of erythropoietin and transfusion threshold on neurological recovery after traumatic brain injury: a randomized clinical trial. JAMA 2014;312(1):36-47

2 Giacino JT, Whyte J, Bagiella E, et al. Placebo-controlled trial of amantadine for severe traumatic brain injury. N Engl J Med 2012; 366(9):819-826

3 Diaz-Arrastia R, Kochanek PM, Bergold P, et al. Pharmacotherapy of traumatic brain injury: state of the science and the road forward: report of the Department of Defense Neurotrauma Pharmacology Workgroup. J Neurotrauma 2014;31(2): 135-158

4 Olney JW. Brain lesions, obesity, and other disturbances in mice treated with monosodium glutamate. Science 1969;164(3880): $719-721$ 
5 Ikonomidou C, Turski L. Why did NMDA receptor antagonists fail clinical trials for stroke and traumatic brain injury? Lancet Neurol 2002;1(6):383-386

6 Randall RD, Thayer SA. Glutamate-induced calcium transient triggers delayed calcium overload and neurotoxicity in rat hippocampal neurons. J Neurosci 1992;12(5):1882-1895

7 Choi DW. Ionic dependence of glutamate neurotoxicity. J Neurosci 1987;7(2):369-379

8 Chamoun R, Suki D, Gopinath SP, Goodman JC, Robertson C. Role of extracellular glutamate measured by cerebral microdialysis in severe traumatic brain injury. J Neurosurg 2010;113(3):564-570

9 Weber JT, Rzigalinski BA, Ellis EF. Traumatic injury of cortical neurons causes changes in intracellular calcium stores and capacitative calcium influx. J Biol Chem 2001;276(3):1800-1807

10 Saatman KE, Bozyczko-Coyne D, Marcy V, Siman R, McIntosh TK. Prolonged calpain-mediated spectrin breakdown occurs regionally following experimental brain injury in the rat. J Neuropathol Exp Neurol 1996;55(7):850-860

11 Sun DA, Deshpande LS, Sombati S, et al. Traumatic brain injury causes a long-lasting calcium ( $\mathrm{Ca} 2+)$-plateau of elevated intracellular $\mathrm{Ca}$ levels and altered $\mathrm{Ca} 2+$ homeostatic mechanisms in hippocampal neurons surviving brain injury. Eur J Neurosci 2008; 27(7):1659-1672

12 Saatman KE, Murai H, Bartus RT, et al. Calpain inhibitor AK295 attenuates motor and cognitive deficits following experimental brain injury in the rat. Proc Natl Acad Sci U S A 1996;93(8): 3428-3433

13 Baumgartner HK, Gerasimenko JV, Thorne C, et al. Calcium elevation in mitochondria is the main $\mathrm{Ca} 2+$ requirement for mitochondrial permeability transition pore (mPTP) opening. J Biol Chem 2009;284(31):20796-20803

14 Knoblach SM, Nikolaeva M, Huang X, et al. Multiple caspases are activated after traumatic brain injury: evidence for involvement in functional outcome. J Neurotrauma 2002;19(10):1155-1170

15 Conti AC, Raghupathi R, Trojanowski JQ McIntosh TK. Experimental brain injury induces regionally distinct apoptosis during the acute and delayed post-traumatic period. J Neurosci 1998; 18(15):5663-5672

16 Clark RS, Kochanek PM, Watkins SC, et al. Caspase-3 mediated neuronal death after traumatic brain injury in rats. J Neurochem 2000;74(2):740-753

17 Knoblach SM, Alroy DA, Nikolaeva M, Cernak I, Stoica BA, Faden AI. Caspase inhibitor z-DEVD-fmk attenuates calpain and necrotic cell death in vitro and after traumatic brain injury. J Cereb Blood Flow Metab 2004;24(10):1119-1132

18 Chen W, Zhou Z, Li L, et al. Diverse sequence determinants control human and mouse receptor interacting protein 3 (RIP3) and mixed lineage kinase domain-like (MLKL) interaction in necroptotic signaling. J Biol Chem 2013;288(23):16247-16261

19 Kaiser WJ, Upton JW, Long AB, et al. RIP3 mediates the embryonic lethality of caspase-8-deficient mice. Nature 2011;471(7338): 368-372

20 Liu Q Qiu J, Liang M, et al. Akt and mTOR mediate programmed necrosis in neurons. Cell Death Dis 2014;5:e1084

21 You Z, Savitz SI, Yang J, et al. Necrostatin-1 reduces histopathology and improves functional outcome after controlled cortical impact in mice. J Cereb Blood Flow Metab 2008;28(9):1564-1573

22 Li Y, Yang X, Ma C, Qiao J, Zhang C. Necroptosis contributes to the NMDA-induced excitotoxicity in rat's cultured cortical neurons. Neurosci Lett 2008;447(2-3):120-123

23 Pickford F, Masliah E, Britschgi M, et al. The autophagy-related protein beclin 1 shows reduced expression in early Alzheimer disease and regulates amyloid beta accumulation in mice. J Clin Invest 2008;118(6):2190-2199

24 Clark RS, Bayır H, Chu CT, Alber SM, Kochanek PM, Watkins SC. Autophagy is increased in mice after traumatic brain injury and is detectable in human brain after trauma and critical illness. Autophagy 2008;4(1):88-90
25 Luo CL, Li BX, Li QQ et al. Autophagy is involved in traumatic brain injury-induced cell death and contributes to functional outcome deficits in mice. Neuroscience 2011;184:54-63

26 Zhang YB, Li SX, Chen XP, et al. Autophagy is activated and might protect neurons from degeneration after traumatic brain injury. Neurosci Bull 2008;24(3):143-149

27 Michelucci A, Heurtaux T, Grandbarbe L, Morga E, Heuschling P. Characterization of the microglial phenotype under specific proinflammatory and anti-inflammatory conditions: effects of oligomeric and fibrillar amyloid-beta. J Neuroimmunol 2009; 210(1-2):3-12

28 Vespa PM, Miller C, McArthur D, et al. Nonconvulsive electrographic seizures after traumatic brain injury result in a delayed, prolonged increase in intracranial pressure and metabolic crisis. Crit Care Med 2007;35(12):2830-2836

29 Tovar KR, Westbrook GL. The incorporation of NMDA receptors with a distinct subunit composition at nascent hippocampal synapses in vitro. J Neurosci 1999;19(10):4180-4188

30 Kaufman AM, Milnerwood AJ, Sepers MD, et al. Opposing roles of synaptic and extrasynaptic NMDA receptor signaling in cocultured striatal and cortical neurons. J Neurosci 2012;32(12): 3992-4003

31 Papadia S, Soriano FX, Léveillé F, et al. Synaptic NMDA receptor activity boosts intrinsic antioxidant defenses. Nat Neurosci 2008; 11(4):476-487

32 Hardingham GE, Fukunaga Y, Bading H. Extrasynaptic NMDARs oppose synaptic NMDARs by triggering CREB shut-off and cell death pathways. Nat Neurosci 2002;5(5):405-414

33 Karpova A, Mikhaylova M, Bera S, et al. Encoding and transducing the synaptic or extrasynaptic origin of NMDA receptor signals to the nucleus. Cell 2013;152(5):1119-1133

34 Bigford GE, Alonso OF, Dietrich D, Keane RW. A novel protein complex in membrane rafts linking the NR2B glutamate receptor and autophagy is disrupted following traumatic brain injury. J Neurotrauma 2009;26(5):703-720

$35 \mathrm{Tu} \mathrm{W}, \mathrm{Xu}$ X, Peng L, et al. DAPK1 interaction with NMDA receptor NR2B subunits mediates brain damage in stroke. Cell 2010; 140(2):222-234

36 Ferrario CR, Ndukwe BO, Ren J, Satin LS, Goforth PB. Stretch injury selectively enhances extrasynaptic, GluN2B-containing NMDA receptor function in cortical neurons. J Neurophysiol 2013; 110(1):131-140

37 Rao VLR, Dogan A, Todd KG, Bowen KK, Dempsey RJ. Neuroprotection by memantine, a non-competitive NMDA receptor antagonist after traumatic brain injury in rats. Brain Res 2001; 911:96-100

38 Xia P, Chen HSV, Zhang D, Lipton SA. Memantine preferentially blocks extrasynaptic over synaptic NMDA receptor currents in hippocampal autopsies. J Neurosci 2010;30(33):11246-11250

39 Rammes G, Danysz W, Parsons CG. Pharmacodynamics of memantine: an update. Curr Neuropharmacol 2008;6(1):55-78

40 Davies DJ, Crowe M, Lucas N, et al. A novel series of benzimidazole NR2B-selective NMDA receptor antagonists. Bioorg Med Chem Lett 2012;22(7):2620-2623

41 Niogi SN, Mukherjee P, Ghajar J, et al. Structural dissociation of attentional control and memory in adults with and without mild traumatic brain injury. Brain 2008;131(Pt 12):3209-3221

42 Bashir S, Vernet M, Yoo WK, Mizrahi I, Theoret H, Pascual-Leone A. Changes in cortical plasticity after mild traumatic brain injury. Restor Neurol Neurosci 2012;30(4):277-282

43 Schumann J, Alexandrovich GA, Biegon A, Yaka R. Inhibition of NR2B phosphorylation restores alterations in NMDA receptor expression and improves functional recovery following traumatic brain injury in mice. J Neurotrauma 2008;25(8):945-957

44 Kumar A, Zou L, Yuan X, Long Y, Yang K. N-methyl-D-aspartate receptors: transient loss of NR1/NR2A/NR2B subunits after traumatic brain injury in a rodent model. J Neurosci Res 2002;67(6): 781-786 
45 Szaflarski JP, Meckler JM, Szaflarski M, Shutter LA, Privitera MD, Yates SL. Levetiracetam use in critically ill patients. Neurocrit Care 2007;7(2):140-147

46 Lee CY, Chen CC, Liou HH. Levetiracetam inhibits glutamate transmission through presynaptic P/Q-type calcium channels on the granule cells of the dentate gyrus. Br J Pharmacol 2009; 158(7):1753-1762

47 Wakita M, Kotani N, Kogure K, Akaike N. Inhibition of excitatory synaptic transmission in hippocampal neurons by levetiracetam involves $\mathrm{Zn}^{2+}$-dependent GABA type A receptor-mediated presynaptic modulation. J Pharmacol Exp Ther 2014;348(2): 246-259

48 Benge JF, Phenis RA, Bernett A, Cruz-Laureano D, Kirmani BF. Neurobehavioral effects of levetiracetam in patients with traumatic brain injury. Front Neurol 2013;4:195

49 Zou H, Brayer SW, Hurwitz M, Niyonkuru C, Fowler LE, Wagner AK. Neuroprotective, neuroplastic, and neurobehavioral effects of daily treatment with levetiracetam in experimental traumatic brain injury. Neurorehabil Neural Repair 2013;27(9):878-888

50 Bratton SL, Chestnut RM, Ghajar J, et al; Brain Trauma Foundation; American Association of Neurological Surgeons; Congress of Neurological Surgeons; Joint Section on Neurotrauma and Critical Care, AANS/CNS. Guidelines for the management of severe traumatic brain injury. II. Hyperosmolar therapy. J Neurotrauma 2007;24(Suppl 1):S14-S20

51 Kochanek PM, Carney N, Adelson PD, et al. Guidelines for the acute medical management of severe traumatic brain injury in infants, children, and adolescents - second edition. Pediatr Crit Care Med 2012;13(Suppl 1):S1-82

52 Gonda DD, Meltzer HS, Crawford JR, et al. Complications associated with prolonged hypertonic saline therapy in children with elevated intracranial pressure. Pediatr Crit Care Med 2013;14(6): 610-620

53 Cooper DJ, Rosenfeld JV, Murray L, et al; DECRA Trial Investigators; Australian and New Zealand Intensive Care Society Clinical Trials Group. Decompressive craniectomy in diffuse traumatic brain injury. N Engl J Med 2011;364(16):1493-1502

54 Shafi S, Diaz-Arrastia R, Madden C, Gentilello L. Intracranial pressure monitoring in brain-injured patients is associated with worsening of survival. J Trauma 2008;64(2):335-340

55 Chesnut RM, Temkin N, Carney N, et al; Global Neurotrauma Research Group. A trial of intracranial-pressure monitoring in traumatic brain injury. N Engl J Med 2012;367(26):2471-2481

56 Stein DM, Hu PF, Brenner M, et al. Brief episodes of intracranial hypertension and cerebral hypoperfusion are associated with poor functional outcome after severe traumatic brain injury. J Trauma 2011;71(2):364-373, discussion 373-374

57 Lafrenaye AD, McGinn MJ, Povlishock JT. Increased intracranial pressure after diffuse traumatic brain injury exacerbates neuronal somatic membrane poration but not axonal injury: evidence for primary intracranial pressure-induced neuronal perturbation. J Cereb Blood Flow Metab 2012;32(10):1919-1932

58 Laird MD, Shields JS, Sukumari-Ramesh S, et al. High mobility group box protein-1 promotes cerebral edema after traumatic brain injury via activation of toll-like receptor 4. Glia 2014;62(1):26-38

59 Badaut J, Lasbennes F, Magistretti PJ, Regli L. Aquaporins in brain: distribution, physiology, and pathophysiology. JCereb Blood Flow Metab 2002;22(4):367-378

60 Bell MJ, Kochanek PM, Doughty LA, et al. Interleukin-6 and interleukin-10 in cerebrospinal fluid after severe traumatic brain injury in children. J Neurotrauma 1997;14(7):451-457

61 Au AK, Aneja RK, Bell MJ, et al. Cerebrospinal fluid levels of highmobility group box 1 and cytochrome $C$ predict outcome after pediatric traumatic brain injury. J Neurotrauma 2012;29(11): 2013-2021

62 Okuma Y, Liu K, Wake H, et al. Glycyrrhizin inhibits traumatic brain injury by reducing HMGB1-RAGE interaction. Neuropharmacology 2014;85:18-26
63 Simard JM, Woo SK, Schwartzbauer GT, Gerzanich V. Sulfonylurea receptor 1 in central nervous system injury: a focused review. J Cereb Blood Flow Metab 2012;32(9):1699-1717

64 Okuma Y, Liu K, Wake H, et al. Anti-high mobility group box-1 antibody therapy for traumatic brain injury. Ann Neurol 2012; 72(3):373-384

65 Fukuda AM, Adami A, Pop V, et al. Posttraumatic reduction of edema with aquaporin-4 RNA interference improves acute and chronic functional recovery. J Cereb Blood Flow Metab 2013; 33(10):1621-1632

66 Zweckberger K, Hackenberg K, Jung CS, et al. Glibenclamide reduces secondary brain damage after experimental traumatic brain injury. Neuroscience 2014;272:199-206

67 Kagan VE, Wipf P, Stoyanovsky D, et al. Mitochondrial targeting of electron scavenging antioxidants: regulation of selective oxidation vs random chain reactions. Adv Drug Deliv Rev 2009;61(14): 1375-1385

68 Tyurina YY, Poloyac SM, Tyurin VA, et al. A mitochondrial pathway for biosynthesis of lipid mediators. Nat Chem 2014; 6(6):542-552

69 Chu CT, Ji J, Dagda RK, et al. Cardiolipin externalization to the outer mitochondrial membrane acts as an elimination signal for mitophagy in neuronal cells. Nat Cell Biol 2013;15(10):1197-1205

$70 \mathrm{Ji} \mathrm{J}$, Kline AE, Amoscato A, et al. Lipidomics identifies cardiolipin oxidation as a mitochondrial target for redox therapy of brain injury. Nat Neurosci 2012;15(10):1407-1413

71 Okonkwo DO, Povlishock JT. An intrathecal bolus of cyclosporin A before injury preserves mitochondrial integrity and attenuates axonal disruption in traumatic brain injury. J Cereb Blood Flow Metab 1999;19(4):443-451

72 Xiong Y, Gu Q, Peterson PL, Muizelaar JP, Lee CP. Mitochondrial dysfunction and calcium perturbation induced by traumatic brain injury. J Neurotrauma 1997;14(1):23-34

73 Robertson CL. Mitochondrial dysfunction contributes to cell death following traumatic brain injury in adult and immature animals. J Bioenerg Biomembr 2004;36(4):363-368

74 Singh IN, Sullivan PG, Deng Y, Mbye LH, Hall ED. Time course of post-traumatic mitochondrial oxidative damage and dysfunction in a mouse model of focal traumatic brain injury: implications for neuroprotective therapy. J Cereb Blood Flow Metab 2006;26(11): 1407-1418

75 Abdul-Muneer PM, Schuetz H, Wang F, et al. Induction of oxidative and nitrosative damage leads to cerebrovascular inflammation in an animal model of mild traumatic brain injury induced by primary blast. Free Radic Biol Med 2013;60:282-291

76 Sies H. Oxidative stress, introductory remarks. In: Oxidative Stress. London, England: Academic Press; 1985:1-7

77 Thiels E, Urban NN, Gonzalez-Burgos GR, et al. Impairment of long-term potentiation and associative memory in mice that overexpress extracellular superoxide dismutase. J Neurosci 2000;20(20):7631-7639

78 Jones DP. Redefining oxidative stress. Antioxid Redox Signal 2006; 8(9-10):1865-1879

79 Opii WO, Nukala VN, Sultana R, et al. Proteomic identification of oxidized mitochondrial proteins following experimental traumatic brain injury. J Neurotrauma 2007;24(5):772-789

80 Mendez DR, Cherian L, Moore N, Arora T, Liu PK, Robertson CS. Oxidative DNA lesions in a rodent model of traumatic brain injury. J Trauma 2004;56(6):1235-1240

81 Bayır H, Tyurin VA, Tyurina YY, et al. Selective early cardiolipin peroxidation after traumatic brain injury: an oxidative lipidomics analysis. Ann Neurol 2007;62(2):154-169

82 Cristofori L, Tavazzi B, Gambin R, et al. Early onset of lipid peroxidation after human traumatic brain injury: a fatal limitation for the free radical scavenger pharmacological therapy? J Investig Med 2001;49(5):450-458

83 Bayır H, Kagan VE, Tyurina YY, et al. Assessment of antioxidant reserves and oxidative stress in cerebrospinal fluid after severe 
traumatic brain injury in infants and children. Pediatr Res 2002; 51(5):571-578

84 Hamm RJ, Temple MD, Pike BR, Ellis EF. The effect of postinjury administration of polyethylene glycol-conjugated superoxide dismutase (pegorgotein, Dismutec) or lidocaine on behavioral function following fluid-percussion brain injury in rats. J Neurotrauma 1996;13(6):325-332

85 Hall ED, Andrus PK, Smith SL, et al. Pyrrolopyrimidines: novel brain-penetrating antioxidants with neuroprotective activity in brain injury and ischemia models. J Pharmacol Exp Ther 1997; 281(2):895-904

86 Wang GH, Jiang ZL, Li YC, et al. Free-radical scavenger edaravone treatment confers neuroprotection against traumatic brain injury in rats. J Neurotrauma 2011;28(10):2123-2134

87 Marshall LF, Maas AI, Marshall SB, et al. A multicenter trial on the efficacy of using tirilazad mesylate in cases of head injury. J Neurosurg 1998;89(4):519-525

88 Muizelaar JP, Kupiec JW, Rapp LA. PEG-SOD after head injury. J Neurosurg 1995;83(5):942

89 Zorov DB, Juhaszova M, Sollott SJ. Mitochondrial reactive oxygen species (ROS) and ROS-induced ROS release. Physiol Rev 2014; 94(3):909-950

90 Bayır H, Kochanek PM, Kagan VE. Oxidative stress in immature brain after traumatic brain injury. Dev Neurosci 2006;28(4-5): 420-431Review

91 Hall ED, Wang JA, Miller DM. Relationship of nitric oxide synthase induction to peroxynitrite-mediated oxidative damage during the first week after experimental traumatic brain injury. Exp Neurol 2012;238(2):176-182

92 Wang F, Franco R, Skotak M, Hu G, Chandra N. Mechanical stretch exacerbates the cell death in SH-SY5Y cells exposed to paraquat: mitochondrial dysfunction and oxidative stress. Neurotoxicology 2014;41:54-63

93 Wu A, Ying Z, Gomez-Pinilla F. Omega-3 fatty acids supplementation restores mechanisms that maintain brain homeostasis in traumatic brain injury. J Neurotrauma 2007;24(10):1587-1595

94 Sullivan PG, Rabchevsky AG, Waldmeier PC, Springer JE. Mitochondrial permeability transition in CNS trauma: cause or effect of neuronal cell death? J Neurosci Res 2005;79(1-2):231-239

95 Van Houten B, Woshner V, Santos JH. Role of mitochondrial DNA in toxic responses to oxidative stress. DNA Repair (Amst) 2006; $5(2): 145-152$

96 Scafidi S, Racz J, Hazelton J, McKenna MC, Fiskum G. Neuroprotection by acetyl-L-carnitine after traumatic injury to the immature rat brain. Dev Neurosci 2010;32(5-6):480-487

97 Scheff SW, Sullivan PG. Cyclosporin A significantly ameliorates cortical damage following experimental traumatic brain injury in rodents. J Neurotrauma 1999;16(9):783-792

98 Mazzeo AT, Brophy GM, Gilman CB, et al. Safety and tolerability of cyclosporin a in severe traumatic brain injury patients: results from a prospective randomized trial. J Neurotrauma 2009; 26(12):2195-2206

99 Smith RA, Hartley RC, Murphy MP. Mitochondria-targeted small molecule therapeutics and probes. Antioxid Redox Signal 2011; 15(12):3021-3038

100 Smith RA, Murphy MP. Animal and human studies with the mitochondria-targeted antioxidant MitoQ. Ann N Y Acad Sci 2010;1201:96-103

101 Cho J, Won K, Wu D, et al. Potent mitochondria-targeted peptides reduce myocardial infarction in rats. Coron Artery Dis 2007; 18(3):215-220

102 Wipf P, Xiao J, Jiang J, et al. Mitochondrial targeting of selective electron scavengers: synthesis and biological analysis of hemigramicidin-TEMPO conjugates. J Am Chem Soc 2005;127(36): 12460-12461

103 Davalos D, Grutzendler J, Yang G, et al. ATP mediates rapid microglial response to local brain injury in vivo. Nat Neurosci 2005;8(6):752-758
104 Shohami E, Novikov M, Bass R, Yamin A, Gallily R. Closed head injury triggers early production of TNF alpha and IL- 6 by brain tissue. J Cereb Blood Flow Metab 1994;14(4):615-619

105 Fan L, Young PR, Barone FC, Feuerstein GZ, Smith DH, McIntosh TK. Experimental brain injury induces expression of interleukin1 beta mRNA in the rat brain. Brain Res Mol Brain Res 1995;30(1): 125-130

106 Aguzzi A, Barres BA, Bennett ML. Microglia: scapegoat, saboteur, or something else? Science 2013;339(6116):156-161

107 Scherbel U, Raghupathi R, Nakamura M, et al. Differential acute and chronic responses of tumor necrosis factor-deficient mice to experimental brain injury. Proc Natl Acad Sci U S A 1999;96(15): $8721-8726$

108 Chio CC, Chang CH, Wang CC, et al. Etanercept attenuates traumatic brain injury in rats by reducing early microglial expression of tumor necrosis factor- $\alpha$. BMC Neurosci 2013;14:33

109 Baratz R, Tweedie D, Rubovitch V, et al. Tumor necrosis factor- $\alpha$ synthesis inhibitor, 3,6'-dithiothalidomide, reverses behavioral impairments induced by minimal traumatic brain injury in mice.J Neurochem 2011;118(6):1032-1042

110 Su X, Wang H, Zhao J, Pan H, Mao L. Beneficial effects of ethyl pyruvate through inhibiting high-mobility group box 1 expression and TLR4/NF-kenefB pathway after traumatic brain injury in the rat. Mediators Inflamm 2011;2011:807-142

111 Zhang $\mathrm{D}$, Li H, Li T, et al. TLR4 inhibitor resatorvid provides neuroprotection in experimental traumatic brain injury: implication in the treatment of human brain injury. Neurochem Int 2014;75:11-18

112 Sanchez Mejia RO, Ona VO, Li M, Friedlander RM. Minocycline reduces traumatic brain injury-mediated caspase- 1 activation, tissue damage, and neurological dysfunction. Neurosurgery 2001;48(6):1393-1399, discussion 1399-1401

113 Clausen F, Hånell A, Björk M, et al. Neutralization of interleukin1beta modifies the inflammatory response and improves histological and cognitive outcome following traumatic brain injury in mice. Eur J Neurosci 2009;30(3):385-396

114 Tehranian R, Andell-Jonsson S, Beni SM, et al. Improved recovery and delayed cytokine induction after closed head injury in mice with central overexpression of the secreted isoform of the interleukin-1 receptor antagonist. J Neurotrauma 2002;19(8): 939-951

115 Helmy A, Guilfoyle MR, Carpenter KL, Pickard JD, Menon DK, Hutchinson PJ. Recombinant human interleukin-1 receptor antagonist in severe traumatic brain injury: a phase II randomized control trial. J Cereb Blood Flow Metab 2014;34(5):845-851

116 Tapia-Perez J, Sanchez-Aguilar M, Torres-Corzo JG, et al. Effect of rosuvastatin on amnesia and disorientation after traumatic brain injury (NCT003229758). J Neurotrauma 2008;25(8):1011-1017

117 Schneider EB, Efron DT, MacKenzie EJ, Rivara FP, Nathens AB, Jurkovich GJ. Premorbid statin use is associated with improved survival and functional outcomes in older head-injured individuals. J Trauma 2011;71(4):815-819

118 Giunti D, Parodi B, Cordano C, Uccelli A, Kerlero de Rosbo N. Can we switch microglia's phenotype to foster neuroprotection? Focus on multiple sclerosis. Immunology 2014;141(3):328-339

119 Sikoglu EM, Heffernan ME, Tam K, et al. Enhancement in cognitive function recovery by granulocyte-colony stimulating factor in a rodent model of traumatic brain injury. Behav Brain Res 2014; 259:354-356

120 Acosta SA, Tajiri N, Shinozuka K, et al. Combination therapy of human umbilical cord blood cells and granulocyte colony stimulating factor reduces histopathological and motor impairments in an experimental model of chronic traumatic brain injury. PLoS ONE 2014;9(3):e90953

121 Dela Peña I, Sanberg PR, Acosta S, Tajiri N, Lin SZ, Borlongan CV. Stem cells and G-CSF for treating neuroinflammation in traumatic brain injury: aging as a comorbidity factor. J Neurosurg Sci 2014;58(3):145-149 
122 Povlishock JT. Pathobiology of traumatically induced axonal injury in animals and man. Ann Emerg Med 1993;22(6):980-986

123 Povlishock JT, Christman CW. The pathobiology of traumatically induced axonal injury in animals and humans: a review of current thoughts. J Neurotrauma 1995;12(4):555-564

124 Smith DH, Hicks R, Povlishock JT. Therapy development for diffuse axonal injury. J Neurotrauma 2013;30(5):307-323

125 Okonkwo DO, Büki A, Siman R, Povlishock JT. Cyclosporin A limits calcium-induced axonal damage following traumatic brain injury. Neuroreport 1999;10(2):353-358

126 Tang-Schomer MD, Patel AR, Baas PW, Smith DH. Mechanical breaking of microtubules in axons during dynamic stretch injury underlies delayed elasticity, microtubule disassembly, and axon degeneration. FASEB J 2010;24(5):1401-1410

127 Zhilai Z, Hui Z, Anmin J, Shaoxiong M, Bo Y, Yinhai C. A combination of taxol infusion and human umbilical cord mesenchymal stem cells transplantation for the treatment of rat spinal cord injury. Brain Res 2012;1481:79-89

128 Mbye LH, Keles E, Tao L, et al. Kollidon VA64, a membraneresealing agent, reduces histopathology and improves functional outcome after controlled cortical impact in mice. J Cereb Blood Flow Metab 2012;32(3):515-524

129 Büki A, Koizumi H, Povlishock JT. Moderate posttraumatic hypothermia decreases early calpain-mediated proteolysis and concomitant cytoskeletal compromise in traumatic axonal injury. Exp Neurol 1999;159(1):319-328

130 Zafonte RD, Bagiella E, Ansel BM, et al. Effect of citicoline on functional and cognitive status among patients with traumatic brain injury: Citicoline Brain Injury Treatment Trial (COBRIT). JAMA 2012;308(19):1993-2000

131 Patel SP, Sullivan PG, Pandya JD, et al. N-acetylcysteine amide preserves mitochondrial bioenergetics and improves functional recovery following spinal trauma. Exp Neurol 2014;257:95-105

132 Clifton GL, Valadka A, Zygun D, et al. Very early hypothermia induction in patients with severe brain injury (the National Acute Brain Injury Study: Hypothermia II): a randomised trial. Lancet Neurol 2011;10(2):131-139

133 Su E, Bell MJ, Kochanek PM, et al. Increased CSF concentrations of myelin basic protein after TBI in infants and children: absence of significant effect of therapeutic hypothermia. Neurocrit Care 2012;17(3):401-407

134 Miyauchi T, Wei EP, Povlishock JT. Evidence for the therapeutic efficacy of either mild hypothermia or oxygen radical scavengers after repetitive mild traumatic brain injury. J Neurotrauma 2014; 31(8):773-781

135 Reeves TM, Phillips LL, Lee NN, Povlishock JT. Preferential neuroprotective effect of tacrolimus (FK506) on unmyelinated axons following traumatic brain injury. Brain Res 2007;1154:225-236

136 Cantu RC, Gean AD. Second-impact syndrome and a small subdural hematoma: an uncommon catastrophic result of repetitive head injury with a characteristic imaging appearance. J Neurotrauma 2010;27(9):1557-1564

137 Bouma GJ, Muizelaar JP, Stringer WA, Choi SC, Fatouros P, Young HF. Ultra-early evaluation of regional cerebral blood flow in severely head-injured patients using xenon-enhanced computerized tomography. J Neurosurg 1992;77(3):360-368

138 Hall CN, Reynell C, Gesslein B, et al. Capillary pericytes regulate cerebral blood flow in health and disease. Nature 2014; 508(7494):55-60

139 Terpolilli NA, Kim SW, Thal SC, Kuebler WM, Plesnila N. Inhaled nitric oxide reduces secondary brain damage after traumatic brain injury in mice. J Cereb Blood Flow Metab 2013;33(2): 311-318

140 Armstead WM, Kiessling JW, Kofke WA, Vavilala MS. SNP improves cerebral hemodynamics during normotension but fails to prevent sex dependent impaired cerebral autoregulation during hypotension after brain injury. Brain Res 2010;1330:142-150
141 Sinz EH, Kochanek PM, Dixon CE, et al. Inducible nitric oxide synthase is an endogenous neuroprotectant after traumatic brain injury in rats and mice. J Clin Invest 1999;104(5):647-656

142 Salonia R, Empey PE, Poloyac SM, et al. Endothelin-1 is increased in cerebrospinal fluid and associated with unfavorable outcomes in children after severe traumatic brain injury. J Neurotrauma 2010;27(10):1819-1825

143 Macdonald RL, Higashida RT, Keller E, et al. Clazosentan, an endothelin receptor antagonist, in patients with aneurysmal subarachnoid haemorrhage undergoing surgical clipping: a randomised, double-blind, placebo-controlled phase 3 trial (CONSCIOUS-2). Lancet Neurol 2011;10(7):618-625

144 Giannopoulos S, Katsanos AH, Tsivgoulis G, Marshall RS. Statins and cerebral hemodynamics. J Cereb Blood Flow Metab 2012; 32(11):1973-1976

145 Jansen JO, Lord JM, Thickett DR, Midwinter MJ, McAuley DF, Gao F Clinical review: statins and trauma-a systematic review. Crit Care 2013;17(3):227

146 Elkind MS, Sacco RL, MacArthur RB, et al. The Neuroprotection with Statin Therapy for Acute Recovery Trial (NeuSTART): an adaptive design phase I dose-escalation study of high-dose lovastatin in acute ischemic stroke. Int J Stroke 2008;3(3): 210-218

147 ShaikJS, Ahmad M, Li W, et al. Soluble epoxide hydrolase inhibitor trans-4-[4-(3-adamantan-1-yl-ureido)-cyclohexyloxy]-benzoic acid is neuroprotective in rat model of ischemic stroke. Am J Physiol Heart Circ Physiol 2013;305(11):H1605-H1613

148 Poloyac SM, Zhang Y, Bies RR, Kochanek PM, Graham SH. Protective effect of the 20-HETE inhibitor HET0016 on brain damage after temporary focal ischemia. J Cereb Blood Flow Metab 2006; 26(12):1551-1561

149 Fordsmann JC, Ko RW, Choi HB, et al. Increased 20-HETE synthesis explains reduced cerebral blood flow but not impaired neurovascular coupling after cortical spreading depression in rat cerebral cortex. J Neurosci 2013;33(6):2562-2570

150 Hartings JA, Bullock MR, Okonkwo DO, et al; Co-Operative Study on Brain Injury Depolarisations. Spreading depolarisations and outcome after traumatic brain injury: a prospective observational study. Lancet Neurol 2011;10(12):1058-1064

151 Feeney DM, Gonzalez A, Law WA. Amphetamine, haloperidol, and experience interact to affect rate of recovery after motor cortex injury. Science 1982;217(4562):855-857

152 Hovda DA, Sutton RL, Feeney DM. Amphetamine-induced recovery of visual cliff performance after bilateral visual cortex ablation in cats: measurements of depth perception thresholds. Behav Neurosci 1989;103(3):574-584

153 Feeney DM. Pharmacologic modulation of recovery after brain injury: a reconsideration of diaschisis. J Neurol Rehabil 1991; $5: 113-128$

154 Kline AE, Chen MJ, Tso-Olivas DY, Feeney DM. Methylphenidate treatment following ablation-induced hemiplegia in rat: experience during drug action alters effects on recovery of function. Pharmacol Biochem Behav 1994;48(3):773-779

155 Wagner AK, Ren D, Conley YP, et al. Sex and genetic associations with cerebrospinal fluid dopamine and metabolite production after severe traumatic brain injury. J Neurosurg 2007;106(4): 538-547

156 Wagner AK, Scanlon JM, Becker CR, et al. The influence of genetic variations on striatal dopamine transporter and D2 receptor binding after TBI. J Cereb Blood Flow Metab 2014;34(8): 1328-1339

157 Bales JW, Kline AE, Wagner AK, Dixon CE. Targeting dopamine acutely in traumatic brain injury. Open Drug Discov J 2010; 2:119-128

158 Dixon CE, Bales J, Kline AE, Wagner AK. Dopamine mechanisms of injury and recovery after TBI. In: Kobaissy FH, ed. Brain Neurotrauma: Molecular, Neuropsychological, and Rehabilitation 
Aspects in Brain Injury Models. Boca Raton, FL: CRC Press; 2015; In press

159 Kline AE, Yan HQ Bao J, Marion DW, Dixon CE. Chronic methylphenidate treatment enhances water maze performance following traumatic brain injury in rats. Neurosci Lett 2000;280(3): 163-166

160 Wagner AK, Drewencki LL, Chen X, et al. Chronic methylphenidate treatment enhances striatal dopamine neurotransmission after experimental traumatic brain injury. J Neurochem 2009b108(4):986-997

161 Wagner AK, Kline AE, Ren D, et al. Gender associations with chronic methylphenidate treatment and behavioral performance following experimental traumatic brain injury. Behav Brain Res 2007;181(2):200-209

162 Meythaler JM, Brunner RC, Johnson A, Novack TA. Amantadine to improve neurorecovery in traumatic brain injury-associated diffuse axonal injury: a pilot double-blind randomized trial. J Head Trauma Rehabil 2002;17(4):300-313

163 Dixon CE, Kraus MF, Kline AE, et al. Amantadine improves water maze performance without affecting motor behavior following traumatic brain injury in rats. Restor Neurol Neurosci 1999; 14(4):285-294

164 Wang T, Huang XJ, Van KC, Went GT, Nguyen JT, Lyeth BG. Amantadine improves cognitive outcome and increases neuronal survival after fluid percussion traumatic brain injury in rats. J Neurotrauma 2014;31(4):370-377

165 Grelak RP, Clark R, Stump JM, Vernier VG. Amantadine-dopamine interaction: possible mode of action in Parkinsonism. Science 1970;169(3941):203-204

166 Gianutsos G, Chute S, Dunn JP. Pharmacological changes in dopaminergic systems induced by long-term administration of amantadine. Eur J Pharmacol 1985;110(3):357-361

167 Allen RM. Role of amantadine in the management of neurolepticinduced extrapyramidal syndromes: overview and pharmacology. Clin Neuropharmacol 1983;6(Suppl 1):S64-S73

168 Harun R, Wagner AK. The neurobiological basis of pharmacological approaches for patients with traumatic brain injury. In: Levin HS, Shum DHK, Chan RCK. Understanding Traumatic Brain Injury: Current Research and Future Directions. New York, NY: Oxford University Press; 2013:255-300

169 Kline AE, Massucci JL, Ma X, Zafonte RD, Dixon CE. Bromocriptine reduces lipid peroxidation and enhances spatial learning and hippocampal neuron survival in a rodent model of focal brain trauma. J Neurotrauma 2004;21(12):1712-1722

170 Brannan T, Martínez-Tica J, Di Rocco A, Yahr MD. Low and high dose bromocriptine have different effects on striatal dopamine release: an in vivo study. J Neural Transm Park Dis Dement Sect 1993;6(2):81-87

171 Zhu J, Hamm RJ, Reeves TM, Povlishock JT, Phillips LL. Postinjury administration of L-deprenyl improves cognitive function and enhances neuroplasticity after traumatic brain injury. Exp Neurol 2000;166(1):136-152

172 Kraus MF, Maki PM. Effect of amantadine hydrochloride on symptoms of frontal lobe dysfunction in brain injury: case studies and review. J Neuropsychiatry Clin Neurosci 1997;9(2):222-230

173 McDowell S, Whyte J, D'Esposito M. Differential effect of a dopaminergic agonist on prefrontal function in traumatic brain injury patients. Brain 1998;121(Pt 6):1155-1164

174 Verrier JD, Jackson TC, Bansal R, et al. The brain in vivo expresses the 2',3'-cAMP-adenosine pathway. J Neurochem 2012;122(1): $115-125$

175 Kochanek PM, Verrier JD, Wagner AK, Jackson EK. The many roles of adenosine in traumatic brain injury. In: Boison D, Masino S, eds. Adenosine: A Key Link Between Metabolism and Central Nervous System Activity. New York, NY: Springer; 2012:307-322

176 Kochanek PM, Vagni VA, Janesko KL, et al. Adenosine A1 receptor knockout mice develop lethal status epilepticus after experimen- tal traumatic brain injury. J Cereb Blood Flow Metab 2006;26(4): 565-575

177 Wagner AK, Miller MA, Scanlon J, Ren D, Kochanek PM, Conley YP. Adenosine A1 receptor gene variants associated with post-traumatic seizures after severe TBI. Epilepsy Res 2010;90(3):259-272

178 Haselkorn ML, Shellington DK, Jackson EK, et al. Adenosine A1 receptor activation as a brake on the microglial response after experimental traumatic brain injury in mice. J Neurotrauma 2010;27(5):901-910

179 Kim M, Ham A, Kim KY-M, Brown KM, Lee HT. The volatile anesthetic isoflurane increases endothelial adenosine generation via microparticle ecto-5'-nucleotidase (CD73) release. PLoS ONE 2014;9(6):e99950

180 Tas PWL, Eisemann C, Roewer N. The volatile anesthetic isoflurane suppresses spontaneous calcium oscillations in vitro in rat hippocampal neurons by activation of adenosine A1 receptors. Neurosci Lett 2003;338(3):229-232

181 Sachse KT, Jackson EK, Wisniewski SR, et al. Increases in cerebrospinal fluid caffeine concentration are associated with favorable outcome after severe traumatic brain injury in humans. J Cereb Blood Flow Metab 2008;28(2):395-401

182 Boison D. The adenosine kinase hypothesis of epileptogenesis. Prog Neurobiol 2008;84(3):249-262

183 Huber A, Padrun V, Déglon N, Aebischer P, Möhler H, Boison D. Grafts of adenosine-releasing cells suppress seizures in kindling epilepsy. Proc Natl Acad Sci U S A 2001;98(13):7611-7616

184 Baroncelli L, Braschi C, Spolidoro M, Begenisic T, Sale A, Maffei L. Nurturing brain plasticity: impact of environmental enrichment. Cell Death Differ 2010;17(7):1092-1103

185 Rassaf T, Totzeck M, Hendgen-Cotta UB, Shiva S, Heusch G, Kelm M. Circulating nitrite contributes to cardioprotection by remote ischemic preconditioning. Circ Res 2014;114(10):1601-1610

186 Dezfulian C, Shiva S, Alekseyenko A, et al. Nitrite therapy after cardiac arrest reduces reactive oxygen species generation, improves cardiac and neurological function, and enhances survival via reversible inhibition of mitochondrial complex I. Circulation 2009;120(10):897-905

187 Schwarzschild MA, Ascherio A, Beal MF, et al; Parkinson Study Group SURE-PD Investigators. Inosine to increase serum and cerebrospinal fluid urate in Parkinson disease: a randomized clinical trial. JAMA Neurol 2014;71(2):141-150

188 Chip S, Zelmer A, Ogunshola OO, et al. The RNA-binding protein RBM3 is involved in hypothermia induced neuroprotection. Neurobiol Dis 2011;43(2):388-396

189 Jackson TC, Verrier JD, Kochanek PM. Anthraquinone-2-sulfonic acid (AQ2S) is a novel neurotherapeutic agent. Cell Death Dis 2013;4:e451

190 Mahmood A, Lu D, Yi L, Chen JL, Chopp M. Intracranial bone marrow transplantation after traumatic brain injury improving functional outcome in adult rats. J Neurosurg 2001;94(4): 589-595

191 Lu D, Li Y, Wang L, Chen J, Mahmood A, Chopp M. Intraarterial administration of marrow stromal cells in a rat model of traumatic brain injury. J Neurotrauma 2001;18(8):813-819

192 Mahmood A, Lu D, Qu C, Goussev A, Chopp M. Long-term recovery after bone marrow stromal cell treatment of traumatic brain injury in rats. J Neurosurg 2006;104(2):272-277

193 Lu D, Mahmood A, Wang L, Li Y, Lu M, Chopp M. Adult bone marrow stromal cells administered intravenously to rats after traumatic brain injury migrate into brain and improve neurological outcome. NeuroReport 2001;12(3):559-563

194 Riess P, Zhang C, Saatman KE, et al. Transplanted neural stem cells survive, differentiate, and improve neurological motor function after experimental traumatic brain injury. Neurosurgery 2002; 51(4):1043-1052, discussion 1052-1054

195 Hoane MR, Becerra GD, Shank JE, et al. Transplantation of neuronal and glial precursors dramatically improves sensorimotor 
function but not cognitive function in the traumatically injured brain. J Neurotrauma 2004;21(2):163-174

196 Liu SJ, Zou Y, Belegu V, et al. Co-grafting of neural stem cells with olfactory en sheathing cells promotes neuronal restoration in traumatic brain injury with an anti-inflammatory mechanism. J Neuroinflammation 2014;11:66

197 Mahmood A, Wu H, Qu C, Xiong Y, Chopp M. Effects of treating traumatic brain injury with collagen scaffolds and human bone marrow stromal cells on sprouting of corticospinal tract axons into the denervated side of the spinal cord. J Neurosurg 2013; 118(2):381-389

198 Tajiri N, Acosta SA, Shahaduzzaman M, et al. Intravenous transplants of human adipose-derived stem cell protect the brain from traumatic brain injury-induced neurodegeneration and motor and cognitive impairments: cell graft biodistribution and soluble factors in young and aged rats. J Neurosci 2014;34(1):313-326

199 Sun D, Bullock MR, McGinn MJ, et al. Basic fibroblast growth factorenhanced neurogenesis contributes to cognitive recovery in rats following traumatic brain injury. Exp Neurol 2009;216(1):56-65

200 Kleindienst A, McGinn MJ, Harvey HB, Colello RJ, Hamm RJ, Bullock MR. Enhanced hippocampal neurogenesis by intraventricular S100B infusion is associated with improved cognitive recovery after traumatic brain injury. J Neurotrauma 2005;22(6):645-655

201 Bregy A, Nixon R, Lotocki G, et al. Posttraumatic hypothermia increases doublecortin expressing neurons in the dentate gyrus after traumatic brain injury in the rat. Exp Neurol 2012;233(2): 821-828

202 Carlson SW, Madathil SK, Sama DM, Gao X, Chen J, Saatman KE. Conditional overexpression of insulin-like growth factor-1 enhances hippocampal neurogenesis and restores immature neuron dendritic processes after traumatic brain injury. J Neuropathol Exp Neurol 2014;73(8):734-746

203 Deng W, Aimone JB, Gage FH. New neurons and new memories: how does adult hippocampal neurogenesis affect learning and memory? Nat Rev Neurosci 2010;11(5):339-350

204 Blaya MO, Bramlett HM, Naidoo J, Pieper AA, Dietrich WD. Neuroprotective efficacy of a proneurogenic compound after traumatic brain injury. J Neurotrauma 2014;31(5):476-486

205 Loane DJ, Faden AI. Neuroprotection for traumatic brain injury: translational challenges and emerging therapeutic strategies. Trends Pharmacol Sci 2010;31(12):596-604

206 Marklund N, Hillered L. Animal modelling of traumatic brain injury in preclinical drug development: where do we go from here? Br J Pharmacol 2011;164(4):1207-1229

207 Margulies S, Hicks R; Combination Therapies for Traumatic Brain Injury Workshop Leaders. Combination therapies for traumatic brain injury: prospective considerations. J Neurotrauma 2009; 26(6):925-939

208 Eakin K, Baratz-Goldstein R, Pick CG, et al. Efficacy of N-acetyl cysteine in traumatic brain injury. PLoS ONE 2014;9(4):e90617

209 Hoffer ME, Balaban C, Slade MD, Tsao JW, Hoffer B. Amelioration of acute sequelae of blast induced mild traumatic brain injury by $\mathrm{N}$-acetyl cysteine: a double-blind, placebo controlled study. PLoS ONE 2013;8(1):e54163

210 Samuni Y, Goldstein S, Dean OM, Berk M. The chemistry and biological activities of $\mathrm{N}$-acetylcysteine. Biochim Biophys Acta 2013;1830(8):4117-4129

211 Abdel Baki SG, Schwab B, Haber M, Fenton AA, Bergold PJ. Minocycline synergizes with $\mathrm{N}$-acetylcysteine and improves cognition and memory following traumatic brain injury in rats. PLOS ONE 2010;5(8):e12490

212 Haber M, Abdel Baki SG, Grin'kina NM, et al. Minocycline plus Nacetylcysteine synergize to modulate inflammation and prevent cognitive and memory deficits in a rat model of mild traumatic brain injury. Exp Neurol 2013;249:169-177

213 Empey PE, Alexander HL, Ocque AJ, et al. Probenecid increases nacetylcysteine brain penetration following experimental pediatric traumatic brain injury. J Neurotrauma 2012;29:229-230
214 Tang H, Hua F, Wang J, et al. Progesterone and vitamin D: improvement after traumatic brain injury in middle-aged rats. Horm Behav 2013;64(3):527-538

215 Shear DA, Tortella FC. A military-centered approach to neuroprotection for traumatic brain injury. Front Neurol 2013;4:73

216 Chesnut RM. Secondary brain insults after head injury: clinical perspectives. New Horiz 1995;3(3):366-375

217 Jungner M, Grände PO, Mattiasson G, Bentzer P. Effects on brain edema of crystalloid and albumin fluid resuscitation after brain trauma and hemorrhage in the rat. Anesthesiology 2010;112(5): 1194-1203

218 Myburgh J, Cooper DJ, Finfer S, et al; SAFE Study Investigators; Australian and New Zealand Intensive Care Society Clinical Trials Group; Australian Red Cross Blood Service; George Institute for International Health. Saline or albumin for fluid resuscitation in patients with traumatic brain injury. N Engl J Med 2007;357(9): 874-884

219 Chodobski A, Zink BJ, Szmydynger-Chodobska J. Blood-brain barrier pathophysiology in traumatic brain injury. Transl Stroke Res 2011;2(4):492-516

220 Brockman EC, Bayır H, Blasiole B, et al. Polynitroxylated-pegylated hemoglobin attenuates fluid requirements and brain edema in combined traumatic brain injury plus hemorrhagic shock in mice. J Cereb Blood Flow Metab 2013;33(9):1457-1464

221 Shellington DK, Du L, Wu X, et al. Polynitroxylated pegylated hemoglobin: a novel neuroprotective hemoglobin for acute volume-limited fluid resuscitation after combined traumatic brain injury and hemorrhagic hypotension in mice. Crit Care Med 2011; 39(3):494-505

222 Brands J, Kliner D, Lipowsky HH, Kameneva MV, Villanueva FS, Pacella JJ. New insights into the microvascular mechanisms of drag reducing polymers: effect on the cell-free layer. PLoS ONE 2013;8(10):e77252

223 Pacella JJ, Kameneva MV, Brands J, et al. Modulation of precapillary arteriolar pressure with drag-reducing polymers: a novel method for enhancing microvascular perfusion. Microcirculation 2012;19(7):580-585

224 Macias CA, Kameneva MV, Tenhunen JJ, Puyana JC, Fink MP. Survival in a rat model of lethal hemorrhagic shock is prolonged following resuscitation with a small volume of a solution containing a drag-reducing polymer derived from aloe vera. Shock 2004;22(2):151-156

225 Khuman J, Zhang J, Park J, Carroll JD, Donahue C, Whalen MJ. Lowlevel laser light therapy improves cognitive deficits and inhibits microglial activation after controlled cortical impact in mice. J Neurotrauma 2012;29(2):408-417

226 Singleton RH, Yan HQ, Fellows-Mayle W, Dixon CE. Resveratrol attenuates behavioral impairments and reduces cortical and hippocampal loss in a rat controlled cortical impact model of traumatic brain injury. J Neurotrauma 2010;27(6):1091-1099

227 Wu A, Ying Z, Gomez-Pinilla F. The salutary effects of DHA dietary supplementation on cognition, neuroplasticity, and membrane homeostasis after brain trauma. J Neurotrauma 2011;28(10): 2113-2122

228 Dash PK, Johnson D, Clark J, et al. Involvement of the glycogen synthase kinase-3 signaling pathway in TBI pathology and neurocognitive outcome. PLoS ONE 2011;6(9):e24648

229 Valle EJ, Allen CJ, Van Haren RM, et al. Do all trauma patients benefit from tranexamic acid? J Trauma Acute Care Surg 2014; 76(6):1373-1378

230 Kabadi SV, Stoica BA, Loane DJ, Luo T, Faden AI. CR8, a novel inhibitor of $\mathrm{CDK}$, limits microglial activation, astrocytosis, neuronal loss, and neurologic dysfunction after experimental traumatic brain injury. J Cereb Blood Flow Metab 2014;34(3): 502-513

231 Maruta J, Heaton KJ, Kryskow EM, Maule AL, Ghajar J. Dynamic visuomotor synchronization: quantification of predictive timing. Behav Res Methods 2013;45(1):289-300 